\title{
قياس اثر الانفاق العسكري في التكوين الرأسالي الثابت للمملكة العربية السعودية للمدة 1980- 2018
}

د. سعاد عبدالقادر قاسم، كلية الادارة والاقتصاد، جامعة دهوك، أقليم كوردستان العراق

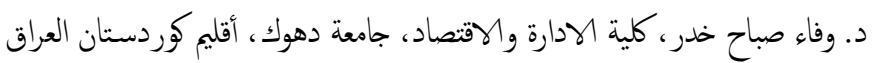

ترتب على تزايد حصة النفقات العسكرية الى الناتج المحلي الاجلالي للمملكة العربية السعودية خلال العقود الثلاثة الماضية اثار سلبية على العديد من المتغيرات الاقتصادية والاجتاعية، الامر الذي حَل اقتصادها الوطني اعباءكثيرة، تمثلت في تراجع العديد من المؤشرات الاقتصادية والاجتاعية نتيجة قلة الفرص الاستثارية الجديدة، ليظهر تأثير ذلك وبشكل مباشر في التكوين الرأسمالي الثابت، مما حمل الاقتصاد السعودي عبء تكلفة الفرصة البديلة. ووفقا لذلك يسعى البحث المى تسليط الضوء على واقع الانفاق العسكري في السعودية مركزا على الاسباب والدوافع التي تقف وراء الانفاق المتزايد بالاعتمد على فرضية مفادها ان تزايد حصة الانفاق العسكري في الموازنة يعود للوفرة المالية المثتئية من الايرادات النفية، كما يفترض البحث وجود علاقة ثكامل مشترك وعلاقة عكسية في المديين القصير والطويل بين الانفاق العسكري ومتغير التكوين الرأسمالي الثابت.

ولغرض تحقيق فرضية البحث تح الاعتماد على منهجة النكامل المشترك باستخدام أنموذج الانحدار الذاتي للإبطاء الموزع (ARDL) technique لقياس اثر الانفاق العسكري في التكوين الرأسلالي الثابت للمملكة العربية السعودية للمدة (1980-2018) ، وخرج البحث بمجموعة من الاستناجات منها اثبات وجود اثر سلبي ومعنوي بين الانفاق العسكري والتكوين الرأسمالي الثابت في المديين القصير والطويل.

كما توصل البحث الى ان سباق التسلح الذي تخوضه السعودية قد اثقل كهل الاقتصاد خاصة في ظل ريعية الدولة واعتادها بشكل شبه كلي على الايرادات المتأتية من النفط مما جعلها اكثر عرضة للصدمات الناتجة عن تقلبات أسعار النفط والتحولات الاقتصادية والسياسية على المستوى العلي. الكلمات المفتاحية: الانفاق العسكري، الاستثمار ، التكوين الرأسمالي ، النمو الاقتصادي، الايرادات النفطية.

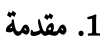

العسكري، احد اهم العناصر الرئيسة للانفاق العام حيث يستأثر بحصة كبيرة من الموازنة العامة على حساب متطلبات واحتياجات القطاع المدني وعلى وفق ذلك تربك فان تزايد حصة الانفاق العسكري نسبة الى الناتج المحلي الاجهالي يترك اثره في اجالي النكوين الرأسالي الثابت، فالتوسع في الانفاق العسكري من شانه تخفيض حصة الانفاق الاستثمري خاصة في ظل ضعف تنويع مصادر الايرادات العامة.

\section{1 مشكلة البحث}

تتركز مشكلة البحث في التزايد الملحوظ في حصة الانفاق العسكري من الانفاق العام، والتي تتخذ منحى تصاعدي ومسيتمر على حساب الاهمية النسبية للعديد من القطاعات والمتغيرات الاقتصادية ومنها النكوين الرأسمالي الثابت، الذي يعد عاملاً معززا لزيادة الانتاجية ومتغيرا فاعلاً في رفع معدلات النمو الاقتصادي.كما ان المبالغ التي ترصدها السعودية والتي تأتي معظمها من الايرادات النفطية لتحقيق تفوقها العسكري ولعب دور القيادة في المنظومة العربية كان من الممكن ان تجعلها في مصاف البلدان المتقدمة لو تم استثمارها في مجالات انتاجية.
استأثر الانفاق العسكري في السعودية بأهمية كيرة وحصة متزايدة ضمن الموازنة العامة للبلد، لتحتل بذلك المركز الوول عربيا والثالث عالميا من حيث الانفاق وذلك حسب مـا جـاء في الاحصـائيات المنشـورة في تقارير معهد السـلام في ستوكهولم (Sipri) اذ وصل الانفاق العسكري للسعودية عام 2018 الم(76.6) مليار دولار من الموازنة العامة، ليأتي ذلك على حساب الأولويات الاقتصادية والاجتاعية للعديد من القطاعات والمتغيرات الاقتصادية بما فهيا التكوين الرأسمالي الثابت الذي تأثر نتيجة تراجع التخصيصات الاستثرية، خاصة في ظل ما يشههد الوضع الاقتصادي في السنوات الاخيرة من تراجع بسبب هبوط اسعار النفط متتصف 2014 واستمرار تداعياته على بجمل الانشطة والقطاعات الاقتصادية. 1.1 ثكن اهمية البحث في تناوله لموضوع الانفاق العسكري، اذ يناقش هذا الموضوع احد اهم الظواهر المرتبطة بالسياسة الانفاقية للمملكة العربية السعودية وما يترتب عليه من تداعيات اقتصادية وسياسية واستراتيجية واجتاعية, باعتبار ان الانفاق 


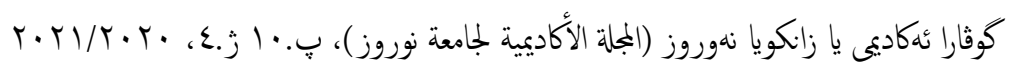

وعلى وفق ما سبق فان السعودية هي اكبر دولة من حيث الانقاق العسكري

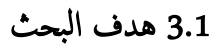

ضمن قائمة الدول العربيـة لذلك ارتأينـا اعداد هــا البحثث لبيـان اثـر السياسـة الانفاقية للسعودية في التكوين الرأسمالي الثابت.

2. المبحث الاول الدراسات السابقة والاطار المفاهيمي والنظري للأنفاق العسكري والتكوين الرأسالي الثابت

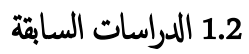

قدمت الادبيات الاقتصادية خلال العقود الثلاثة الماضية دراسات عديدة تناولت موضع العلاقة الجدلية بين الانفاق العسكري والعديد من المتغيرات الاقتصادية والاجتمية من جوانب عديدة، لتُبين بذلك الاختلاف في تفسير شكل وطبيعة العلاقة القائمة بين الانفاق العسكري والعديد من المتغيرات الاقتصادية كالمو. الاقتصادي والاستثار والادخار، كذلك ايجاد تفسير لتباين درجة التأثير من بلد لبلد اخر اعتادا على طبيعة الهياكل الاقتصادية ودرجة التقدم الاقتصادي ونظام الحكم السائد، فهناك دراسات اثبتت الاثر الايجابي للانفاق العسكري في النمو الاقتصادي ضمن تجارب بعض الدول، في هين اكدت دراسات اخرى على الاثار السلبية، خاصة في المدى الطويل ـ ووفقا لأهداف بكثنا سنستعرض الدراسات التي تناولت الاثر السبي للانفاق العسكري وعلى النحو الاتي:

دراسة ( 1980, Ronald p smith ) استخدمت هذه الدراسة بيانات لعينة تتكون من 14 بلد متقدم صناعيا ضمن منظمة التعاون الاقتصادي والتنيـة للمـدة 1954 - 1973، استنادا المى فرضية مفادهـا ان انخفاض الاستثار في بلدان عينة الدراسة يعود للتزايد في النفتات العسكرية على اعتبار ان الخفاض الاستثمار كان بمثابة تكلفة الفرصة البديلة لبلدان عينة الدراسة ومن خلال القياس الكمي اظهرت نتائج الدراسة العلاقة السلبية بين سبة الانفاق العسكري للناتج المحلي الاجهالي ونسبة الاستثمار الى الناتج المحلي الاجلالي حيث ان حصة الاستثار الى الناتج المحلي الاجمالي تعتمد على تخصيصات الانفاق العسكري ومعدل النمو الاقتصادي والطلب الكلي سواء تم التقدير باعتماد سلاسل زمنية او بيانات(Panal data). دراسة (Chowdhury, 1991) تناولت هـذه الدراسة قيـاس العبء Panal ( الاقتصادي للانفاق العسكري لـ 55 بلاًاً ناميا باستخدام بيـات (data اجـراء تكمـل مشـترك وقيـاس السببية بـين الانفــاق العسكري والنمـو
- تسليط الضـوء على الجانب النظري للانفـاق العسكري وتشـيص اهم دوافعه ومحدداته ونقاط الضعف في السياسـة الانفاقيـة للمملكة العربيـة السعودية في ظل تزايد حجم نقاتها العسكرية .

بيان اهمية التكوين الرأسالي الثابت في اقتصاد أي دولة الى جانب التطرق الى الاثار السلبية التي يتركها الانقاق المتزايد على التسليح في الاقتصاد خاصة لدولة مثل السعودية تتوافر لديها الى حد كبير امككانات النهوض الاقتصادي.

- التقدير الكمي للعلاقة الاقتصادية بين قيمة الانفاق العسكري واجهالي التكوين الرأسمالي في الاجلين القصير والطويل.

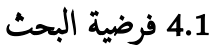

يفترض البحثث وجـود علاقة معنويـة ذات اثر سـلبي بين الانفـاق العسكري والتكوين الرأسمالي في المـدين القصير والطويلـلكـا يفترض البحث ان تـوفر مصادر التمويل خاصة الايرادات المتأتية من صادرات النفط والغناز تلفب دورا كبيرا في تزايد حصة الانفاق العسكري مقارنة بباقي قنوات الانفاق العام.

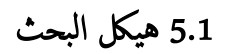

اعتمد البحث على المنهج التحليلي الوصفي، لما امكن الحصول عليه مـن البيـانات التي تم توظيفها حسب خدمة البحث حيث اعتمدنا على بيانات لسلسة زمنية

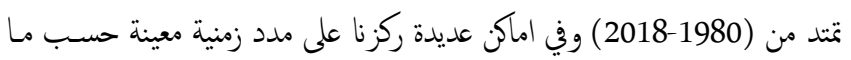
تطلب الامر ووفقا لما توفر من البيانات.كما اعممد البحث على الجانب القياسي في تقدير العلاقة التي تربط الانفاق العسكري بالتكوين الرأسمالي اذتم استخدام انموذج (ARDL) لبيان معنوية العلاقة بين المنغيرات في المديين القصير والطويل وبالاعتماد على برنامج (Eviews10) (1). 6.1 مدة البحث والعينة ومبررات اختيارها تم اعتماد سلسلة زمنية تمتد من (1980-2018) وذلك كأساس للتحليل والتقدير باعتبار ان هذه المدة شهدت تزايد حصة الانفاق العسكري ضمن الموازنة العامة للسعودية وشهدت العديد من الازمات والحروب كحرب الخليج الاولى والثانية ومسن ثم الحـرب عسلى الارهـاب والحـرب في الـيمن الى جانـب قيـام السعودية ولسنوات بتمويل الجماعات المسلحة التي كلفت السعودية مبالغ كبيرة. 


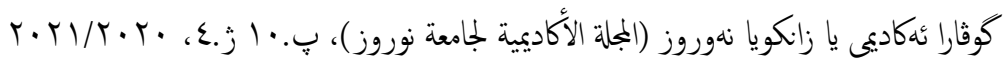

(106) بلد نامي للمدة (1988-2010) اعتادا على فرضية مفادها ان اثار الانفاق العسكري في النمو الاقتصادي متفاوتة ومتباينة نظرا لعدم تجانس البيئة الاقتصادية والاجتماعيـة والسياسـية وججم الاختلالات اليكليـة لبلدان عينة الدراسة. وبعد ان تم استخدام ادوات القياس الكمي استنتج

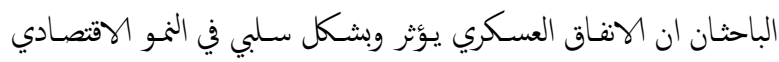
لعينة البحث لكن نسبة الثأثير تتباين بين المجموعات وهذا الاختلاف في التـاثير يعود لبعض الامور كاختلاف مستويات الدخل وحالة الصراع الداخلي والخـارجي للبلد ومـدى وفرة الموارد الطبيعـة ودرجة الانفتاح

$$
\text { الاقتصادي ويجم المعونات. }
$$

دراسة (2014, Hou and Chen) اهتمت هذه الدراسة بتقدير اثر الإنقاق العسكري في الاستثمار لعينـة تتكون مـن 13 بلدا مختـارا للمـدة 2012-1971 باستخدام منهجيـات متعـددة للتكامـل المشـترك اعتمادا على كلى بيانات لسلاسل زمنية لكل بلد بشكل منفصل اضافة الى قياس النكمل المشـترك اعتمتادا على بيـاتات (Panal data) توصلت الدراسـة الى ان الانفاق العسكري يؤثر وبشكل سلبي في الاستثمار مسن خلال مزاحمنه للاستثخار الخاص في تلك البلدان خلال مدة الدراسة. دراسة (M Ensar Yesilyurt \& J Paul Elhorst,2017) ركزت هذه الدراسة في الدوافع الرئيسة لسباق التسـح الذي تخوضه العديد مـن البلدان، وللوصول الى نتـائُ منطقيـة قام الباحثان بتقسيم عينة الدراسـة المتكونـة مـن (144) بـادا الى اربعـة بمموعـات وفقـاً لاعتبـارات جغرافيـة واقتصادية وسياسية من ضمنها البلدان النفطية في الثرق الووسط خلال المدة (1993-2007) اعتادا على بيانات السلاسل الزمنية وكذلك بيـانات بصيغة (panal data)، كما وقد تم اجراء الانحدار ومن ثم تطبيق طريقة العزوم المعممة (GMM) وتبين من النتائج ان الانفاق العسكري الذي يتت

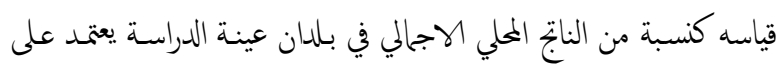
ججم الانفاق العسكري لبلدان اخرى سواء كانت من دول الجوار ضمن الحدود الوقليمية او حتى لو لم تكن من دول الجوار. دراسة (Rahman, et al, 2019) حاولت هذه الدراسة تقدير العلاقة بين الانفاق العسكري والنمو الاقتصادي من خلال أنموذجين يقيس الاول اثر الانفاق العسكري في معدلات النمو الاقتصادي امـا الانموذج الثـاني
الاقتصادي وتبين من النتائج ان الانفاق العسكري كان ذو اثر سلبي في النمو الاقتصادي ل 25 بلد وذو اثر موجب في النمو الاقتصادي لـ 7 بلدان اما باقي العينة والتي بلغت 18 دولة فلم يظهر تأثير للانفاق العسكري في النمو الاقتصادي وكان من ضمن الاستنتاجات التي توصلت لها الدراسة ان جحم الاثر الذي تركه الانفاق العسكري في النمو الاقتصادي لعينة الدراسة اعتمد على الواقع الاقتصادي والسياسي للبلد وججم الانقاق على التسليح اضافة الم قيمة الصادرات من الاسلحة وقيمة مـا يتم استيراده من اسلحة

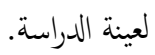
دراسة ( Scheetz,1991 ) استخدمت هذه الدراسة بيانات ( Panal data لعينة من اربعة بلدان في امريكا اللاتينية (تشيلي والارجنتين وبيرو والارغــواي ) للمــــ 1969-1987. وتم قيــاس العلاقـة بـين الانفـاق العسكري والاستثمار وذلك مـن خلال اعتماد نسبة الانفاق العسكري للناتج المحلي الاجهالي ونسبة اجهالي الاستثار الى الناتج المحلي الاجمالي وتوصلت الدراسة الى ان اثر الانفاق العسكري كان سـالبا في الاستثفار بنوعيـه المبـاشر وغير المبـاشر نظرا لتزايـد حصة الانفـاق العسكري في تركي موازنات تلك البلدان مقارنة بما تم تخصيصه من مبالخ للانفاق الاستثاري. دراسة (Ron P Smith, 2001) ركزت هذه الدراسة في تحليل العلاقة بين نمو النفقات العسكرية والاستثمار اعتمادا على بيـانات (Panal data) لـ 28 دولة ضمن منظمة النعاون الاقتصادي والتنيـة من ضمهـا 17 دولة متقدمة اقتصاديا، خلال المدة 1960-1997 واستخدمت للتقدير منهجية VAR والى جانب استخدام متغير الانفاق العسكري كنسبة الى اجمالي الناتج المحلي الاجهالي باعتباره متغير مستقل تم قيساس بعض المتغيرات الاقتصادية الاخرى نهـا الناتج المحلي الاجمالي ونصيب الفرد من الناتج المحلي بالأسعار الثابتة واجهالي تكوين راس المال الثابت باعتباره مقياس للاستثمار وتوصلت الدراسة المى ان التأثير السلبي للأنفاق العسكري في اجالي التكوين الرأسالي الثابت ظهر في الكثير من البلدان خاصة تلك التي توجه مبالغ ضخمة من ميزانيتها لاستيراد الاسلحة اضافة الى الدول التي تواجه صدمات اقتصادية بشكل متكرر. دراسة ( J. Paul Dunne \& Nan Tian, 2013 تناولت هذه الدراسة قياس اثر الانفاق العسكري في النمو الاقتصادي لعينة تتكون من 


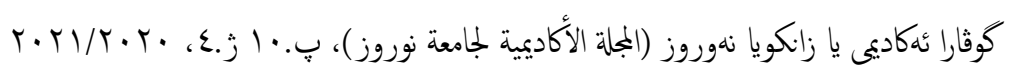

دراسـة (Seyfettin,et al, 2020) هـدفت هـذه الدراسـة الى تحليـل العلاقة بين تقلبات اسعار النفط والنفقات العسكرية لبلدان مجلس النعاون

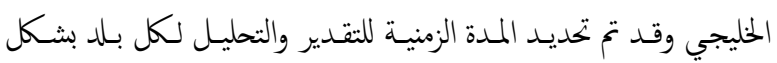
منفصل حسب ما توفر من البيانات ولأجل ذلك تمت الاستعانة بمنهية ARDL لأجراء النكمل المشترك، التي اظهرت علاقة معنوية وطردية بين الانفاق العسكري واسعار النفط، فع ارتفاع اسعار النفط تتزايد الايرادات النفطية وتتكون الفوائض المالية، مما يحفز الانفاق العسكري لبلدان العينة باستثناء السعودية التي اسيتمرت في زيادة انفاقها العسكري رغز هبوط اسعار النفط لسنوات عديدة ـ وبررت الدراسة ذلك في ان السعودية حينما تزيد من انفاقها العسكري او تحافظ على مستوى انفاقها فان ذلك يتم من خلال ترشيق نققاتها الاستثرارية والتنموية كذلك نققاتها الجارية هذا فضلا عن ما تتمتع به من فرص تمويل على المستوى الدولي. 2.2 مفهوم الانفاق العام و الانفاق العسكري يعد الانفاق العام اداة رئيسة من ادوات السياسة المالية التي تعبر عن دور الدولة في الحياة الاقتصادية و توجيه النشـاط الاقتصادي، لتحقيق النمو والاستقرار الاقتصادي والاجتاعي، إذ يشكل احد مكونات الطلب الكلي ومحدد رئيس للمنو الاقتصادي وتكوين راس المال الثابت وبخاصة الانفاق الاستثاري العام، الذي يعد وفورات خارجية للاستثار الخاص • ووفقا لذلك فالنفقات العامة هي مبالغ نقدية تخج من الذمة المالية للحكومة او احدى السلطات المكونة لها , او مبلغ من النقود يخرج من ذمة شخص عام بهدف تحقيق منفعة عامة، ولنلك فان الهدف من النفقات العامة هو لإشباع الحاجات العامة وليس اشباع حاجات خاصة ويتم ذلك ملك عن طريق مرافق عامة يتم ادارتها من قبل الدولة ككا ان كفاءة النفقات العامة ترتبط بعقدة الدولة في تحديد المجلات ذات الاهمية اي كيفية انفاق الموارد المحدودة باكبر قدر مككن من الكفاءة والفعالية في كافة المجالات ، امـاكيفية الانفاق فهذا

$$
\text { يعود الى رؤية الدولة حسب الاهمية (عطية، 2011، 3). }
$$
لقد قدمت الادييات الاقتصادية والسياسية الى جانب المنظات الدوليـة تعاريف متتوعة للأنفاق العسكري غطت معظمها جميع الجوانب اذ تم تعريفها بأجلالي المبالغ النقدية التي يتم انفاقها للأغراض العسكرية وما يتعلق بها والتي تشمل كل ما يتم تحديده من تخصيصات توجه لوزارة الدفاع والداخلية وهيئات الامسن والمؤسسات العاملة في مجال حفظ الامن وما ينثق عنها من هيئات ووحدات حكومية تعمل
فيقيس اثر قيمة الصادرات العسكرية في النمو الاقتصادي ولتأكيد ذلك لك اجرت الدراسة تحليل الهخدار المنتعدد لعينة متكونة من (85) بلاسا للمدة (2017-1998) وباسـتخدام متغـيرات عديـدة منهـا النمـو في النـاتج المهلي الاجلالي وحصة الفرد من الناتج المحلي الاجالي والفائض والعجز في الميزان النجاري والمديونية وقيمة الصادرات العسكرية وقيمة الاستيرادات العسكرية ونسبة الانفاق العسكري الى الناتج المحلي الاجهالي، توصلت الدراسة الى ان الانفاق العسكري ذو تثأثير سلبي في النمو الاقتصادي للكثير من بلدان عينة الدراسة نظرًا لأهـا تخصص رؤوس اموال اقل للاستثمار في مجالات

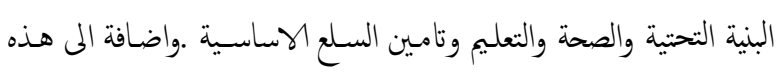
النتيجة توصلت الدراسة الى نتيجة اخرى تظهر ان الاثر الايجابي في النمو

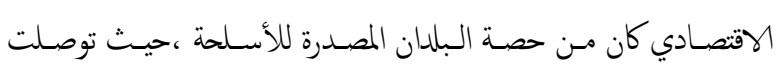
الدراسـة الى وجـود نكامـل مشـترك وعلاقـة معنويـة موجبـة بـين قيمـة الصادرات العسكرية والنمو الاقتصادي واستنتجت ان الإنفاق العسكري الموجه نخو تصنيع و تصدير الأسلحة يعد أداة فعالة في السياسة التجارية والعلاقـات الدوليـة لتـأمين النمـو الاقتصـادي والحفــاظ عـلى الوسـتقرار

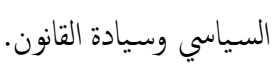
دراسة (Nan tian,2019) اهتمت هذه الدراسة بتحليل العلاقة بين العوائد النفطية و تمويل ميزانيات الدفاع والانفاق العسكري لغرض بيان اثر تقلبات اسعار النفط في قيمة الانفاق العسكري لمجموعة من البلدان المصدرة للنفط التي يتخذ انفاقها العسكري منحى متصاعد في ظل ارتفاع اسعار النفط. ولإثبات ذلك تم الهتماد على سلاسل زمنية للمدة 2009-2017 وتم اجراء تكامـل مشـترك لعينـة الدراسـة ومـن ثم اجـراء مقـارنات بين صدمات أسعار النفط للسنوات 2008-2009 و2014-2016 و النغيرات الحاصلة في قيمة الإنفاق العسكري. استنجت الدراسة ان صدمة اسعار النفط التي تسبت بأحداث تقلبات في العوائد النفية تلعب دورًا كبيرا في تحديد مستوى الإنفاق العسكري في الاقتصادات المصدرة كما هو الحال في دول إفريقيـا وأمـريكا الجنوبيـة والشرسق الأوسط مثلـ أنتـولا وأذربيجـان والعراق وجنوب السودان وفنزويلا، اما المملكة العربية السعودية فلم تؤثر صدمات اسعار النفط في انفاقها العسكري رغز اعتمادها على الايرادات النفطية بشكل كير. 


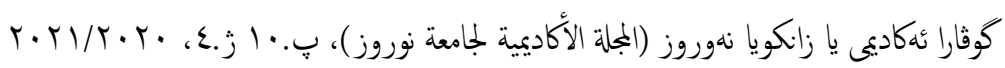

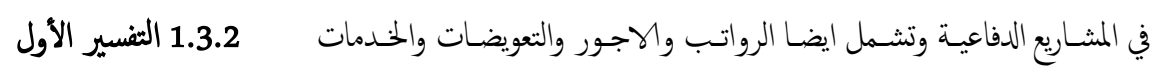

هذا التفسير مبني على افتراض امكانية حدوث تكامل وترابط بين القطاعات المدنيـة والقطاع العسكري التي تجعل مـن القطاع العسكري وسـيلة لتنشـيط الاقتصاد نظرا لاحتياج المؤسسات العسكرية لخدمات البحث والتطوير التي من شانها تفعيل نشاط الكثير من الوحدات الاقتصادية والكاديمية باتجاه تحقيق مرود اقتصادي يعود نفهه على المجتع ككل الى جانب تامين خدمات الدفاع وحفظ الامن التي تساهم بدورها في ايجاد بيئة مستقرة وأمنة وهذا بدوره يحفز الاستثمار المحلي والاجنبي ليخلق بذلك العديد من فرص العمل ويحسن من مستوى التعليم والمهارات ومن شـان ذلك توسيع نطاق السوق وزيادة القدرة التنافسية للبلد وبشكل تديئي (Yildirim \& Sezgin,2005,53-61) ،كما يككن ومن خلال الانفاق العسكري اعتاد تكنولوجية حديثة يعود نفها على القطاع المدني. يضاف الى ذلك المهارات والخبرات المكتسبة في النشاط العسكري ومدى انتفاع افراد الجمتع منها ومن جهة اخرى ينظر للانفاق العسكري كالية لتطوير البنية التحتية مـن

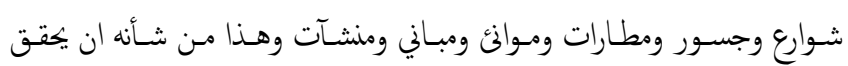
وفورات خارجية لمشروعات القطاع الخاص وللأفراد بصورة عامة. كما وينظر للانفاق العسكري من زاوية ان الانفاق العسكري من شـانه توفير الامن والامان للبلد فع توافر وانتشار مؤسسات حفظ الامن، يعم الامـان

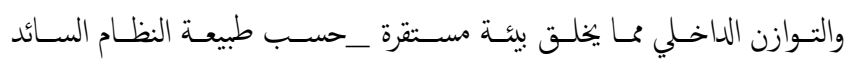
ومساراته_ وهذه البيئة تحفز على الاستثار وتنويع القاعدة الانتاجية .ضافة الى لى ان تحقيق التوازن الخارجي سيعمل على الحدد مـ بعض الخخاوف التي تنشأ مـن التهديـدات الخارجيـة التي تعـد عوامـل طـاردة للاستتفار ودافع لهروب رؤوس

الاموال وهجرة العقول. (Rahman, et al, 2019,37)

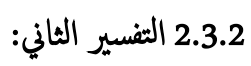
يشير الى الاثار السلبية للانفاق العسكري مستندا على فكرة امكانيـة حدوث تداخل وتنافس ما بين القطاعين العسكري والمدني لينعكس ذلك التنافس والتزام على حساب القطاع الخاص واستثناراته الامر الذي يزيد من جفوة الموارد ويعمق من حدة الاختلالات الهيكلية، ويلحق الضرر بالاقتصاد، خاصة حينا ينظر الى الموضوع من ناحية تكلفة الفرصة البديلة وما سيضحى به البلد من موارد اقتصادية

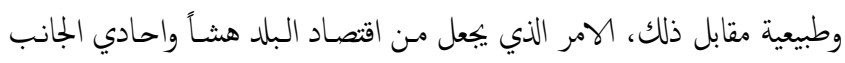
معتمدا على الريع في معظم ايراداته كما هو حال الاقتصاد السعودي. الاجتماعيـة (كالطبابـة والتعلـيم والسـكن)، المدفوعـة مـن قبـل الدولة للكـوادر العسكرية والعاملين في المؤسسات العسكرية هذا المى جانب مـا يتم انفاقه فعليا على المشـتريات واللموازم غير العسكرية يضـاف الى ذلك تخصيصـات الصيانة والبحث والتطوير (عبدالعزيز، 2018،25). كما وقد تم اعطاء تفصيل لمضامين الانفاق العسكري من قبل معهد السلام في ستوكهولم (Sipri) وعلى النحو الاتي: اجالي الانفاق الجاري والدوري لمتطلبات العمل كالتنقل والملمس والمسكن والغذاء.

تخصيصات سنوية لتعليم الكوادر العسكرية وذلك من حلال فتح دورات لمو الامية او الانفاق على الدراسة في المعاهد والكليات العسكرية . تخصيصات توجه لتمويل برامج التدريب واعداد الكوادر العسكرية . كل ما يتم انفاقه على عمليات شراء الاسلحة او انتاجحا محليـا اضافة الى مـا ينفق على صيانتها وتجديدها. كل ما يتم انفاقه على بنـاء المباني والمنشـآت الخاصة بيئة العمل ومتطلباته

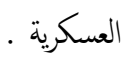

الانفاق الموجه نحو قنوات البحث والتطوير سواء داخل المؤسسـات العسكرية او خارجما بضمها الجامعات والمؤسسات العامة والخاصة . وفي حالات عديدة تشمل النققات العسكرية على المعونات العسكرية التي تقدهـا بعض الجهات او البلدان ( الفارس، 1993، 67). 3.2 العلاقة بين الانفاق العسكري والنمو الاقتصادي تنفاوت وتتباين الرؤى والتحليلات للعديد من الادييات حول ماهية العلاقة الاقتصادية بين الانفاق العسكري والنمو الاقتصادي، ويأتي هـذا التبـاين مسن الاختلاف والنايز بين البيئة الاقتصادية والاجتاعية والسياسية لكل بلد وفتا لما يتضمنه هذا الانفاق من مزايا ومنافع تمثثل بتوفير فرص العمل وايرادات متحققة من ذلك ووفقا لجملة التكليف التي يتحملها الجمتع وما يتزتب على ذلك من اثار وانعكاسات على الاقتصاد القوي ككل لذلك فان العلاقة بين الانفاق العسكري والنمو الاقتصادي هي علاقة جدلية بإمكانا عرضها وفقا للتفسيرين الآتين: 


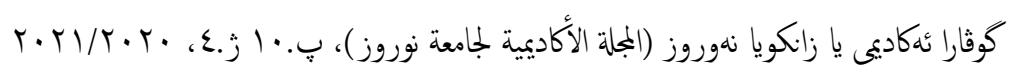

لاختلاف نمط التكنولوجية لكلا القطاعين والاهـداف المتوخاة من استخداهما يضاف الى ذلك ان التدريب على بعض الفنون الانتاجية التي تتطلب مشروعاتها رؤوس اموال كثيفة لا يستـفاد منهـا السـكان في القـرى والارياف (الخطيـب،

(29، 2008

\section{2 قياس العبء الاقتصادي والاجثاعي للأنفاق العسكري}

يتم قياس العبء الاقتصادي للأنفاق العسكري بطرائق متعددة، منها اخذ قيمة هذا الانفاق كنسبة الى الناتج المحلي الاججالي ومعرفة اثره في القطاع المدني ثم بيان تأثير ذلك في المتغيرات الاقتصـادية الاخرى كالاستهلاك والاستثمار وطبيعة

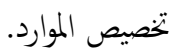

اما الطريقة الاخرى لحساب العبء الاقتصادي فتتم من خلال احتساب نسبة الانقاق العسكري الى الانفاق العام وهذا المؤشر يعد الككثر استخداما إذ انه يعكس تفضـيلات واهتمامـات متخـذيّ القـرارات، اذكلماكانـت الدولة بوضـع اقتصادي جيد ارتفت التخصيصات المالية للأمسن والدفاع كما ان هنالك طريقة اخرى تتمثل بتحديد نصيب الفرد مـن هـذا الانفـاق فضلا عن ايجـاد نسبة

الاستيرادات العسكرية الى الاجالية (Daniel P, 1991, 17) .

ان العبء الاقتصادي للانفاق العسكري يكمن في جوانب عديدة فمن ناحية النكليف تعد تكاليف الانتاج العسكري اعلى بكثير من النكليف الانتاجية لسلع ومتتجات القطاع المدني فـن خلال دراسة صادرة عن البنك الدولي عام 1999 تبين ان انتاج الطائرة المدنية يتزتب عليه نكاليف اقل بكثير من المبالغ المخصصة

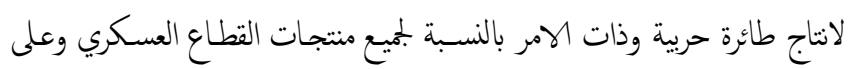
وفق ذلك فان الانتاج الصناعي المدني ينمو بمعدلات تفوق معدلات نمو القطاع العسكري يضاف الى ذلك ان صادرات القطاع المدني تعد عامل محفز لاستقطاب رؤوس الاموال الاجنبية رغز ان ما يخصص لها مـن الميزانية اقل مـن ما ترصده Sipri Military Expenditure الكثير مـن الدول للانفـاق العسكري

.(Database, 2020 اما بالنسبة للعبء الذي ينج عن استيرادات الاسلحة، فقد شهدت استيرادات المملكة العربية السعودية من الاسلحة والذخائر زيادة بنسبة(130\%) خلال الفتزة (2015-2019). مقارنة بالفتزة (2010-2015)، مما يجعلها أكبر مستورد للأسلحة في العالم إذ بلغ انفاق السعودية على الأسلحة التي استوردتها (12\%) من اجالي استيرادات الأسلحة على المستوى العالمي في تلك الفترة كما ان عملية تويل الانفاق العسكري في الكثير من الدول تتم من خلال فرض الضرائب وزيادة
وفي هذا الخصوص توفر الادبيات الاقتصادية للمدرسة الكلاسيكية دلائل تشير الى أن زيادة الإنفاق العسكري من شـأنه احداث تباطؤ في النمو الاقتصادي اذ تؤودي الزيادة في الإنفـاق العسـكري الى انخفـاض مسـتوى الاسـتثفار الخـاص والمدخرات المحلية، وانخفاض الاستهلاك بسبب انخفاض الطلب الكلي. وهذا مـا اكدته دراسات عديدة منها (Hou and Chen 2014,62) فارتفاع مستوى الإنفـاق العسـكري سـيؤدي إلى زيادة في سـعر الفائسدة، الأمـر الذي سـيزام الاستثثارات الخاصة .كما و قد يؤدي الانفـاق العسكري المتزايـد الى احداث تشـوهات في الاسعار النسـية لعنـاصر الانتـاج والموارد مـا يؤثر في الطاقـة الانتاجية كما قد تتركز انشطة البحث والتطوير على التقدم العلمي في المجال العسكري على حساب المجالات الانتاجية والاقتصادية ما يفقد الاقتصاد عوائد مالية وفرص للتطور والنهوض (KUIMOVA, ALEXANDRA, 2020,

ووفقا ملا تم ذكره واعتقادا على مـا اشـارت اليه الدراسات السياسية والاقتصادية التي تم عرضها، فان امكانية تحقيق نمو اقتصادي في ظل الانفاق العسكري مسالة تعمد على حالة البلد هل هو مستورد للاسلحة ام مصدر لها كذلك على قدرة البلد في استثار الايرادات المتحققة، في القنوات والقطاعات الانتاجية الاخرى، لتعم بذلك الفائدة وتتحقق المنفعة الاجتماعية شريطة اخذ تكلفة الفرصة البديلة في

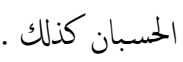
اما بالنسبة للبلدان المستوردة للأسلحة والتي توجه سـويا مبالخ ضخمة للأنفاق العسكري فان مسالة النمو والتطور الاقتصادي سيتعمد ايضا على نكلفة الفرصة البديلة وما سيضحي به البلد مقابل ذلك، ايضا مدى توفر مقومات النهوض بما فيها وفرة الموارد وتنوعها والسياسة الاقتصادية للبلد والنظام الاقتصادي القائم، فعند توفر ما يتلاءم مع متطلبات النمو الاقتصادي سيكون هنالك فرص لتحقيق معلات اعلى من الناتج المحلي الاجهالي ومع المحافظة على ذلك المحدل وزيادته بالإمكان تحتيق نهوض افتصادي خاصة اذا ما رافق ذلك استثمار موجه نحو تنمية راس المال البشري مـن خلال النعليم والتدريب وتقديم المهارات وخلق انماط

سلوكية ختنافة (Yildirim and Sezgin,2005,53-61). وفيا يخص الجانب السلبي للأنفاق العسكري فيمكن تحليله من خلال انتقاد مدى الاتنفاع الحقيقي من الاثار الايجابية التي تم الحديث عنها فنيا يخص مشاريع البنية التحتية فعظمها يقام ويشيد في مناطق نائية لا يعود نفعها على افراد الجمتع كما ان المنفعة المتحققة من التكنولوجية الممتمدة محدودة لا يستفاد منها القطاع المدني نظرا 


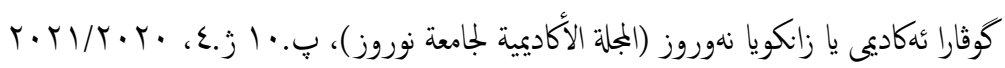

\section{2 التكوين الرأسالي الثابت واهيته الاقتصادية}

يعد التكوين الرأسالي الثابت من ابرز المتغيرات الاقتصادية التي يُعول عليه في النهوض الاقتصادي، خاصة بعد ما تبين دوره المحوري والفاعل في تجارب الكثير من البلدان المتقدمة والنامية على حد السواء ،كونه يمثل أحد ركايز النمو الاقتصادي ومسؤولاً عن السمات الإيمابية والسلبية لاتجاهاته، اذ من شأنه زيادة الطاقة الإنتاجية للاقتصاد عن طريق الاستثمار المنتج والمحافظة على الطاقة الإنتاجية القائمة والعمل على توسيعها، فضلاً عن كونه من الوسائل الفعالة والرئيسة

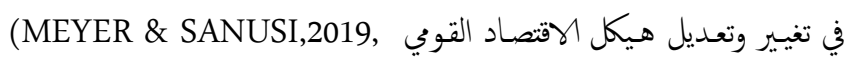

وعلى وفق ما سبق يكنن تعريف إجلالي تكوين رأس المال الثابت بأنه الإضافة إلى

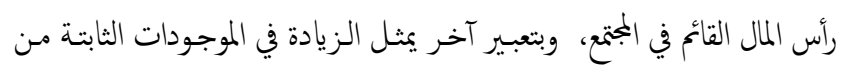
السلع الرأسهالية التي تدخل نطاق الاقتصاد القوي والتي تتميز عن السلع الاستهلاكية بأن الأخيرة تستهلك كلياً خلال دورة الإنتاج وتبقى عادة سـنة بينها تشترك السلع الرأسالية في عملية الإنتاج لعدة سنوات. ان أهمية تكوين راس المال الثابت ودوره في العملية الإنتاجية همم جداً وذلك لأنه يوفر العنصر المادي للعملية الإنتاجية وتتزايد أهمينة في ظل ظروف التقدم العلمي و التكنولوجي، حيـث يتعاظم المسـتوى التقني لوسـائل الإنتاج وبذلك تتعاظم نسبة الالات والمعدات الحديثة التي توفر وتوسع الطاقات الإنتاجية القائمة أو تقوم بخلق الجديدة منها، وبها فهو يستأثر بدور كير في عملية النمو الاقتصادي، وقد اكدت ذلك الادبيات الاقتصادية ، خاصة ضمن انموذج النمو الاقتصادي لادم سميث وانوذج (هارود - دومار ) اذ يبينّ سميث وهارود - دومار ان النكوين الرأسالي هو اساس المنو الاقتصادي وان هذا التكوين يثأتى من الادخار إذ يمثل هذا العنصر من الاستثار تدفقا يضاف إلى رصيد رأس المال في المجتع، ويشمل الإنفاق على شراء السلع الرأسمالية كالالات والمعدات وهي السلع التي تستخدم لالإنتاج سلع وخدمات أخرى، إضافة إلى الاستثمار في المباني والعقارات والأبهزة الخختلفة المستخدمة في العمليـة الإنتاجية (أمـد, 2006، 45) ، حيث ينتج النكوين الرأسالي عندما يخصص جزء من الدخل الحالي كادخار لكي يتم استثاره

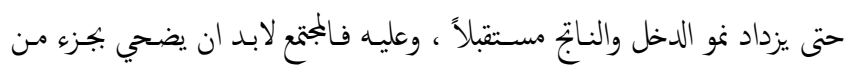
الاستهلاك الجاري وتعبئة المدخرات الوطنية من اجل زيـادة الطاقات الانتاجيـة

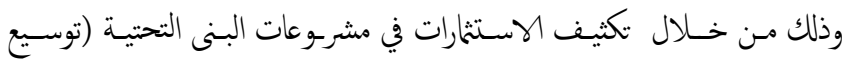
شبكة الطرق الداخلية والخارجية وانشـاء الجسور والمطارات والموانع والمدارس
معدل الاستقطاع الضريبي كذلك من خلال اعتماد الموارد الاقتصادية الخخصة للأفراد وللقطاعات الاقتصادية او مسن خلال لجوء الحكومات نحو الاقتراض والذي غالبا ما يترك يجزأ كيرا في الموازنة العامة والميزان التجاري وعلى وفق ذلك فان من شان طرق التمويل هذه خفض المدخرات المحلية لمستويات متدنية جدا فاخغفاض الادخار الوطني، يقلل من نسبة الاستثار المستقبلي، وهذا يدلي بآثاره السلبية على الاقتصاد الوطني كلل. لقد أثتتت التجارب في البلدان العربية أن تفامً أزمة المديونية الخارجية لم ينجم عن

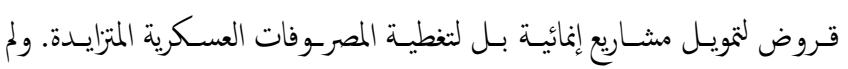
تستطع هذه الدول معالجة أزمتها عن طريق سياسات مالية صائبة بل بتدخل

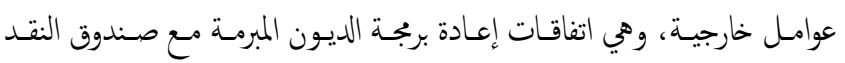
الدولي(Gülbahar, 2016, 42).

\subsection{2 العبء الاجتماعي للانفاق العسكري}

نستدل من احتساب بمحوعة من المؤشرات على اجمالي العبء الاقتصادي والاجتاعي للانفاق العسكري بالاعتماد على طريتّان لمعرفة مقدار العب واثاره والطريقتان تتمثلان بالاتي: أ. اجراء مقارنة فيا بين ما يتم انفاقه على التسليح ومـا يتم انفاقه فعليا على بلى

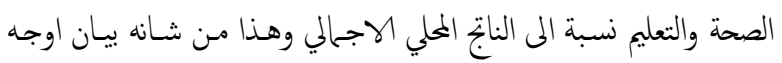
القصور والضعف في الخدمات المقدمة مـن قبل الحكومة لأفراد الشعب ومدى تأثير ذلك النقص في الاقتصاد ككل وعلى جميع الشرائح .

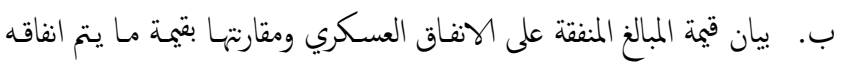
على الصحة والتعليم والرعاية الاجتماعية. ان معرفة مقدار الانفاق العسكري ويجم التخصيصات السـنوية له مـن الموازنة العامة يعكس الواقع الاقتصادي والاجتماعي والسياسي للبلد ويبين مدى قدرة البلد على النهوض الاقتصادي ومدى تأثر نشاطه بما يتم توجيه للانفاق العسكري خاصة بعد التأكد من قيمة ما يتم تخصيصه للجوانب الاكثر اهية وهي الصحة والتعليم والاستثمار. وهذا مـا يفسر- وبوضوح حالة عدم الاستقرار الاقتصادي والازمات الداخلية الناجمة عن تفشي البطالة وانخفاض حصة الفرد من الناتج المحلي الاجمالي وما بتقخض عن ذلك من تداعيات تجعل من عملية الاصلاح اكثر تعقيدا وصعوبة ( 92- Collier \& Hoeffler,2006 , 89 ). 


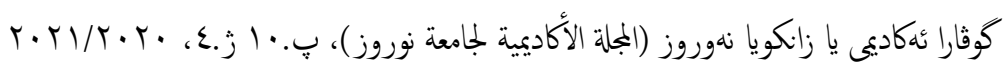

جدول 1: المؤشرات الاقتصادية للسعودية للمدة 1980-2018

\begin{tabular}{|c|c|c|c|c|c|}
\hline الاستثار & النسبة الاتفاق النسكري المي المجلي & الجالي تكوين & الأفاق & الايرادات & البيان \\
\hline 20.926 & 12.613359 & 37,626 & 31,381 & 101,421 & 1980 \\
\hline 20.172 & 13.265239 & 40,369 & 36,543 & 111,546 & 1981 \\
\hline 20.706 & 17.720246 & 42,423 & 40,712 & 73,263 & 1982 \\
\hline 21.637 & 16.972927 & 42,311 & 33,056 & 44,829 & 1983 \\
\hline 27.545 & 19.004348 & 38,214 & 35,502 & 36,282 & 1984 \\
\hline 21.453 & 16.995201 & 31,993 & 29,318 & 25,930 & 1985 \\
\hline 19.46 & 15.793201 & 33,975 & 24,823 & 18,060 & 1986 \\
\hline 17.718 & 16.896414 & 32,341 & 26,083 & 20,427 & 1987 \\
\hline 19.689 & 15.151882 & 29,668 & 23,873 & 20,205 & 1988 \\
\hline 19.445 & 13.390317 & 29,164 & 22,558 & 24,095 & 1989 \\
\hline 15.684 & 14.024293 & 32,345 & 28,349 & 40,129 & 1990 \\
\hline 19.986 & 12.469808 & 37,871 & 27,035 & 43,607 & 1991 \\
\hline 22.964 & 11.284158 & 39,500 & 25,409 & 46,527 & 1992 \\
\hline 25.055 & 12.465372 & 42,661 & 26,934 & 38,621 & 1993 \\
\hline 20.357 & 10.644782 & 36,107 & 23,244 & 38,138 & 1994 \\
\hline 20.286 & 9.2784684 & 37,898 & 20,489 & 43,547 & 1995 \\
\hline 18.571 & 8.4680778 & 35,223 & 20,456 & 54,272 & 1996 \\
\hline 18.778 & 11.000935 & 36,696 & 27,780 & 53,343 & 1997 \\
\hline 22.949 & 14.311038 & 39,087 & 32,091 & 32,569 & 1998 \\
\hline 21.514 & 11.381936 & 42,465 & 28,562 & 44,880 & 1999 \\
\hline 19.317 & 10.534403 & 44,494 & 31,480 & 70,866 & 2000 \\
\hline 19.623 & 11.419005 & 45,177 & 33,531 & 59,788 & 2001 \\
\hline 19.693 & 9.7580638 & 46,006 & 29,432 & 63,815 & 2002 \\
\hline 19.493 & 8.6871185 & 52,836 & 29,641 & 82,272 & 2003 \\
\hline 19.865 & 8.0815557 & 64,966 & 32,892 & 110,746 & 2004 \\
\hline 20.175 & 7.7305992 & 79,866 & 39,720 & 161,871 & 2005 \\
\hline 22.215 & 7.8483674 & 95,927 & 45,246 & 190,468 & 2006 \\
\hline 26.473 & 8.5270512 & 115,731 & 52,118 & 205,452 & 2007 \\
\hline 27.296 & 7.3534385 & 129,714 & 51,152 & 280,998 & 2008 \\
\hline 31.715 & 9.6171993 & 123,597 & 52,568 & 161,613 & 2009 \\
\hline 30.926 & 8.5656774 & 136,703 & 54,713 & 214,897 & 2010 \\
\hline 26.971 & 7.2300533 & 158,066 & 55,456 & 317,614 & 2011 \\
\hline 26.542 & 7.676603 & 165,920 & 62,761 & 337,480 & 2012 \\
\hline 26.47 & 8.9761277 & 175,231 & 71,925 & 321,888 & 2013 \\
\hline 28.751 & 10.677906 & 188,348 & 84,772 & 284,558 & 2014 \\
\hline 35.127 & 13.325672 & 195,315 & 90,409 & 152,910 & 2015 \\
\hline 30.933 & 9.8727383 & 167,890 & 64,698 & 136,194 & 2016 \\
\hline 28.862 & 10.251356 & 169,069 & 72,136 & 170,241 & 2017 \\
\hline 20.926 & 8.7747191 & 165,462 & 76,400 & 194,358 & 2018 \\
\hline
\end{tabular}

https://data.albankaldawli.org/country/saudi-arabia?view=chart

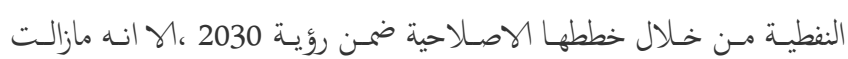

الإيرادات النفطية تهيمن على هيكل الايرادات العامـة، فوفقا لإحصائيات مؤسسة

النقد السعودي لعام 2018 فان مساهمة القطاع النفطي تصل الى (43.2\%) مـن

اجهالي النـاتج المحلي الاجهالي، الامـر الذي يثـير الى ارتكاز السياسـة الانفاقيـة

للسعودية على الحيرادات النفطية فيا يخص ججم واتجاهات انفاقها العام ومقدار مـا
والجامعات والمستشفيات ومشاريع الطاقة وشـبكات الميـاه والاتصال وغيرها) التي

من شانها ان تساعد على اقامة المشاريع الانتاجية وتوسـيع النشـاط الاقتصـادي . لذلك فالمقدار الذي يستطيع ان يضيفه المجتمع المى كميـة راس المال يؤثر على معدل النمو الاقتصادي لذلك المجتمع ( كطان، 2009، 17).

6.2 تحليل الانفاق العسكري في السعودية..... الاسباب والدوافع تنوعت الاسباب والاهداف التي دفت السعودية لزيادة انفاقها العسكري، فمنذ عقد الثانينيـات ومع نشـوب الحرب العراقية ـالايرانيـة ولأهـداف خاصة قامت السعودية بدع العراق في حربه مع ايران، رغبة منها في المحافظة على توازن القوى في المنطقة، ولتستأثر بالأهمية في منطقة الخليج، بيـد ان اجتيـاح العراق للكويت احدث خللً في توازن القوى واضعف من قدرتها على حهاية اقتصادها وحدودها من التهديدات الهنية والذي جاء متزامنا مع تحولات خارجية ودولية تمثلت بانهيار الاتحاد السوفيتي وتمركز السـلطة والقيـادة الدوليـة للولايات المتحدة، الامـر الذي دفـع السـودية وبمثــاركة دول الخلـيج المى تشـكيل تحـالف مـع الدول الصـناعية

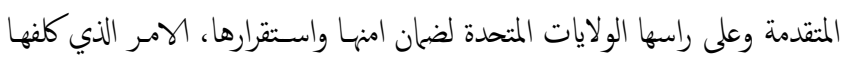
مبالغ طائلة مما جعلها تهدر الكثير من الاموال المتأنية من ايرادات النفط والغاز في صفقات شراء اسـلحة وذخـائر على حسـاب العديـد مـن المتنـيرات والانشطة الافتصادية (Saab , 2014,21). وبالنظر الى معطيـات الجـدول (1) يتبـين لنـا التزايـد الملحـوظ في ججم الانفــاق العسكري اذ بلغ $(36,543)$ دولار نهاية عام 1981 بعد ان كان يبلغ (31,381) مليار في عام 1980 ليتزايد عن ذلك في عام 1982 ويصل الى (40,712) مليـار، وتعود هذه الزيادة المى اسباب عديدة منها نشوب حرب الخليج الاول، إذكان لها اثر واضح في تـلك الزيادة، حيـث قـدمت السـودية الكثـير مـن المسـاعدات العسكرية للعراق هـا المى جانب مـا خصصته مـن نفتات لماية حدودها وانهـا

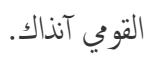

كما وفرت زيادة الايرادات النفطية نتيجة قيـام السعودية بزيادة صادراتها النفطية رغز هبوط اسعار النفط بعد عام 1980 فرص تحقيق فوائض مالية كان لها دور كبير في توفير التمويل اللازم لشراء المزيد مـن الاسلحة وتوسيع نطاق مؤسسـات الامن والدفاع إذ بلغت الهيرادات النفطية $(111,546)$ مليار عام 1981 بعد ان كانت (101,421) عام 1980، ان الزيادة في حصة الانفاق العسكري كانت اكبر مـن الزيادة في حصة التكوين الرأسـالي الثابت مما يـل على اسـتئثار الانفاق العسكري بأهمية اكبر . و رغز ان السعودية تحاول تقليل الاعتماد على الهيرادات 


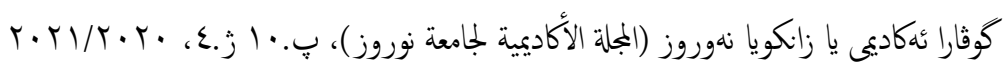

أدى غزو التحالف الدولي بقيادة الولايات المتحدة للعراق في عام 2003 الى جانب ارتفـاع اسعار النفط، إلى تصـاعد سريـع في الإنفـاق العسكري للسـودية مـن (29,641) مليار دولار عام 2003 إلى(54,713) مليـار دولار عام 2010 ومع الارتفاع في اسعار النفط اخذت الايـرادات النفطيـة تزّايد الامـر الذي سـامي بدوره في زيادة حجم الانفاق العسكري خاصة في ظل التدهور الامني في العراق وافغانستان بعد الاحتلال الامريكي وتفشي- الجماميع الارهابية وما تبح ذلك من أحداث ثورات الربيح العربي في تونس ومصر- وسوريا واليمن وليبيا ليصل الى لى لئل (90,409) مليـار دولار عـام 2015 ليضع الإنفـاق العسكري على رأس قائمسة قطاعات الإنفاق العام، وتعزى هذه الزيادة الكبيرة في ججم الانفاق العسكري رغز انخفاض الإيرادات العامة نتيجة الهبوط الحاد في اسعار النفط منتصف 2014 الى تمويل نققات الحرب في اليمن ودع الجماعات المسلحة، ورغز الخفاض الانفاق العسـكري في السـنوات 2016، 2017، 2018 الى (64,698) (72,136) و (76,400) مليار دولار على التوالي، اله انه ووفقا لإحصائيات معهد ستوكهولم للسلام، احتلت السعودية المرتبة الثالثة لعام 2018 ضمن قائمة كبار البلدان مـن

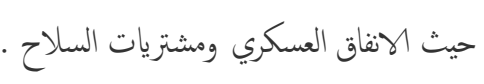

ان الزيادة الحاصـة في قيمـة الانفـاق العسكري كانت على حسـاب الاهميـة الاقتصادية للتكوين الرأسمالي الثابت فالزيادة في الانفاق العسكري كانت اكبر من الزيادة الحاصلة في قيمة التكوين الرأسالي. ووفقا للتقرير الاقتصادي لمؤسسة النقد العربي السعودي لعام 2019 فان نسبة الانتـاج المحلي للأسلحة والذخائر في السعودية لاتتجاوز (2\%) لذلك فهي تتخذ مـن ذلك مبرراً لزيادة انفاقها على استيراد الاسلحة بذلك الكم الهائل. هذا اضافة الى الدوافع الرئيسة والتي تعود الى

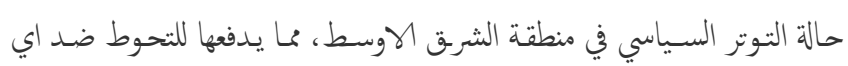
تغيـير قدـ هــدد امنها ومصـالمها في المنطقة المى جانب ارضـاء الادارة الامريكية واعتاد ذلك وسيلة لتعزيز علاقاتها الاقتصادية والسياسية مع الادارة الامريكية مقابل تقديم الحماية لها خاصة في ظل توفر القدرة المالية للدولة على الانفاق الامر الذي خلق لها العديد من المشاكل المالية الخطيرة تتجلى في عجز الميزانية العامة التي

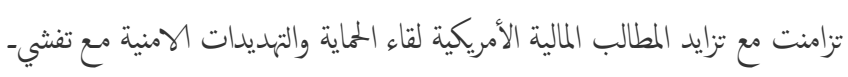

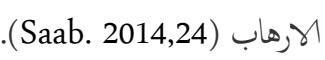

ووفق معطيات الجدول (1) يتيبن لنا ان السعودية تخصص مبالغ كيرة من موازنتها

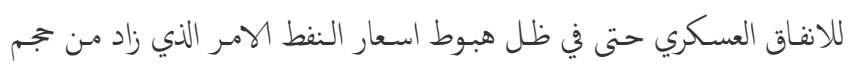
الدين العام ليصل نهاية عام 2018 الى (23.71) نسبة الى اجلالي الناتج المحلي
تخصصه للانفاق العسكري، لذلك فحع الهبوط المسيتمر والتدرييم لأسعار النفط وتحولات السوق النفطية وفي ظل تخمة المعروض النفطي بعد عام 1980 اخذت النفقات العسكرية تأخذ منحى تنـازلي خلال النصف الثاني من عقد الثانينيات، لتسجل اعلى قيمة لها في عام 1982 اذ بلغت (40,712) مليار دولار وادنى قيمة خلال ذات المدة في عام 1989إذ بلغت (22,558) مليار دولار. خلال عقد الثانينيـات نلاحظ انه وفي سـنوات عديدة كانت العلاقة مـا بين الانفاق العسكري والنكوين الرأسمالي الثابت علاقة عكسية، ففي عام 1986 تزايـدت قيمة النكوين الرأسمالي مـن $(31,993)$ مليـار دولار عـام 1985 الى (33,975) مليار عام 1986 وانخفضت في اعوام اخرى امام تزايد حصة الانفاق العسكري، اما الزيادة الحاصلة في قيمة النكوين الرأسمالي الثابت كانت لسنوات عديدة زيادات متناقصة مقارنة بالزيادة الحاصلة في الانفاق العسكري، كما وتُبين لنا معطيات الجمدول (1) ذات العلاقة العكسية والزيادة المتناقصة لمتغير نسبة الاستثفار الى الناتج المحلي الاجمالي مقارنة بالتغيرات الحاصلة في نسبة الانفاق

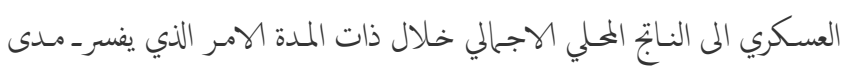
اولوية الانفاق العسكري ضمن هيكل الانفاق العام للسعودية وفي عقد التسعينيات فقد كان لاجتياح العراق للكويت اثر واضح في زيادة الايرادات النفية للسعودية، نظرا لتأثر السوق النفطية بحالة عدم الاسـتقرار السياسي الامر الذي دفع السعودية لزيادة انفاقها العسكري من $(22,558)$ مليـار

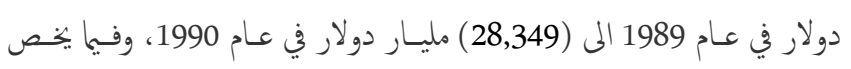
التكوين الرأسمالي الثابت فقد استمر في زيادته المتناقصة مقارنة بالتغيرات الحاصلة في قيمة الانفاق العسكري إذ بلخ اجمالي التكوين الرأسمالي الثابت في عام 1990 (32,345) مليار دولار بيد انه وفي السنوات اللاحقة اخذت النفقات العسكرية تتأربح ارتفاعا وانخفاضـا لتصل اعلى قيمة لها في عـام ( 1998) لتبلغ (32,091) مليـار دولار، وادنى قيمـة في عـام 1996، إذ بلغـت (20,456) مليـار دولار ، ويعزى ذلك لانسحاب العراق من الكويت والوجود المسيتمر للقوات الأمريكية في الخليج بعد عام 1991 الامر الذي حد من مخاوف دول الخليج وخاصة السعودية

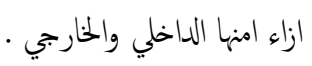
كما ويلاحظ من خلال بيانات الجدول(1) ان هجهات 11/ ايلول ومـا اعقيها من ون حرب على الإرهاب لم ينتج عنه زيادة في انقاق السعودية بل الخفض انفاقها في عام 2002 المى (29,432) مليار دولار بعد ان كان (33,531) مليـار دولار في عام 2001 في هين نجد زيادة متواصلة في الانفاق العسكري منذ عام 2003 إذ 


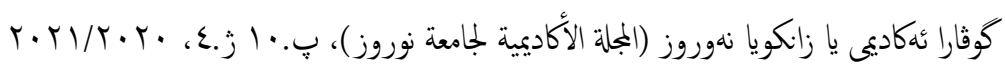

ويثل هذا العنصر-من الاستثمار تدفقا يضاف إلى رصيد رأس المال في

المجتمع.

وعليه فان العلاقة بين المتغيرين نكون عكسية فيا يخص الاقتصاد السعودي الذي

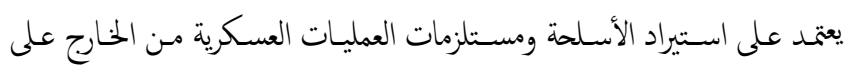
عكس البلانان المصدرة للأسلحة والخدمات العسكرية، عليهه فانه وفي بعض الحالات فأنّ العلاقة بين المتغيرات الاقتصادية لا يكن قياسها بدقة إذ أنّ الظواهر الاقتصادية معقدة ومركبة، وتتأثر بعوامل عديدة وتؤثر هي بتلك العوامل، فلا يكن عزل تأثير المتغيرات بعضها عن بعض فهي متداخلة ويتباين اثرها من دولة

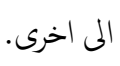

military Expenditure

Gross fixed capital formation

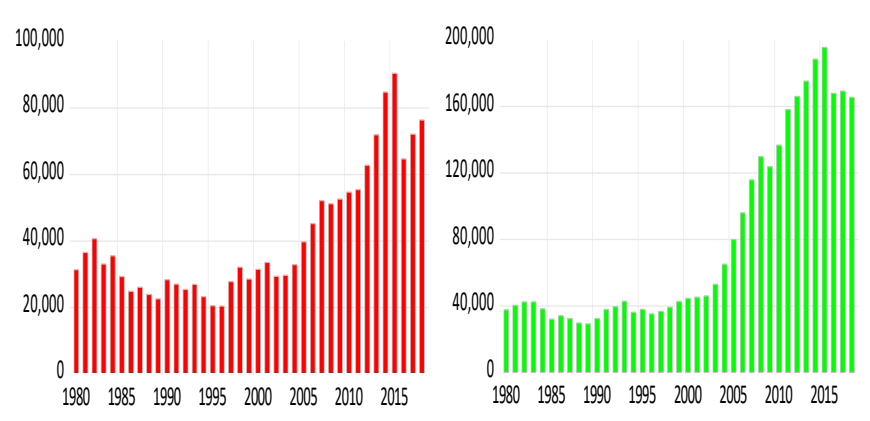

المصدر من اعداد الباحثتان بالاعتاد على بيانات الجدول (1)

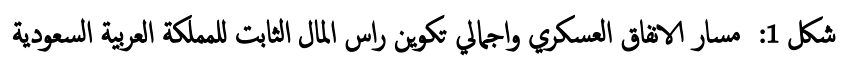
خلال المدة 1980-2018

2.4 صياغة العلاقة الدالية للأنموذج القياسي

بعد ان تم تحديد المتغيرات الداخلة في الانموذج يتطلدب تحديد الشكل الرياضي للأفموذج من اجل اثبـات او نفي تأثير المثغير المستقل على المتغير التـابع ولهذا الغرض تم صياغة الدالة على النحو الاتي:

$\mathrm{CA}=\mathrm{B}_{\mathrm{O}}+\mathrm{B} 1 \mathrm{GM}+\mathrm{Ui}$

إذ تمثل CA : النكوين الرأسمالي الثابت B0 تثنل: الحد الثابت

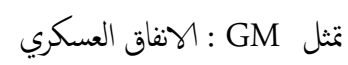

والأموذج الذي لدينا يأخذ الصيغة اللوغاريتمة المزدوجة للسعودية باستخدام

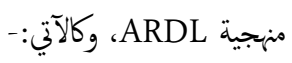

$$
\begin{aligned}
\Delta \mathrm{LCA}=\mathrm{la}_{\mathrm{o}}+ & \sum_{\mathrm{n}=1}^{\mathrm{r}} \mathrm{B}_{1} \Delta \mathrm{lCA}_{\mathrm{t}-1}+\sum_{\mathrm{n}=0}^{\mathrm{n}} \mathrm{B} 2 \Delta \mathrm{lGM}_{\mathrm{t}-1} \\
& ++\emptyset_{1} \mathrm{lCA}_{\mathrm{t}-1}+\emptyset_{2} \mathrm{lGM}_{\mathrm{t}-1} \\
& +\varepsilon_{\mathrm{t}} \ldots \ldots \ldots .
\end{aligned}
$$

وفقاً لبيـانات منشـورة في التقريـر الاقتصادي السـنوي لعام 2019 على موقع مؤسسة النقد العربي، وهذه النسبة عالية بالنسبة لاقتصاد كالسعودية يمتلك وفرة

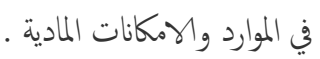
ان استمرار توجيه جزء كبير مـن الميزانية للانفاق العسكري، يشكل عائق امام فرص جذب الاستثار المحلي والاجنبي مما يفقد الاقتصاد السعودي فرص تنويع رن اقتصاده في ظل ما هو متوفر لديه من فرص متعددة وامكانات متنوعة. 4. المبحث الثالث: المذجة القياسية لعينة البحث لغـرض الوصـول الى هـــف البحـث وتخقيـق فرضــيته يتطلـب ربـط النظريـة الاقتصـادية بالجانب التطبيقي وذلك مـن خلال استخدام أسـاليب الاقتصاد القيـاسي للحصـول عـلى نتـابُج وتفــيرات منطقيــة في إيضـاح السـلوك السـائد للمتغيرات المعتمدة في البحث. فلالقتصاد القياسي يسعى لقياس وتحليل العلاقات الاقتصادية التي تحددها النظرية الاقتصادية، اعتمادا على الاسـاليب الرياضية والاحصائية لاختبار تلك النظرية من جهة، ولوضع السياسات او لاتخاذ القرارات المستقبلة من بحة اخرى. وعلى وفق ذلك فان الانموذج المعتمد يتطلب توصيفه على النحو الاتي: - 20 - مل

\section{4 توصيف متغيرات الأموذج}

سيتم الاعتماد على النظرية الاقتصادية في تحديد شكل العلاقة بين المتغيرات المستخدمة في الأثموذج وكيفية اتجاههاكي يستطيع الباحثين بناء انموذج قياسي يفسر اثر الانفاق العسكري في اجمالي تكوين راس المال الثابت تم يتم وصف

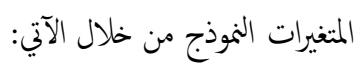
المتغير المستقل: الانفاق العسكري، وهو المتغير المستقل في الاتموذج وقد تم اختياره بوصفه متغير ذو تأثير على اجالي تكوين راس المال الثابت نظرا لاستئناره بحصة كبيرة في الموازنة العامة للسعودية خاصة في ظل مـا يتركه من اثار سلبية على النشاط الاقتصادي اذ ان النغيرات الحاصلة في ججم. الانفاق العسكري ستنعكس بدورها على كل من الادخار والاستثمار ليؤثر بذلك على التكوين الرأسمالي. المتغير التابع: ويتثثل بـ اجالي تكوين راس المال الثابت، تم اختيار هذا المتغير لماله له من اهية ودور ايجابي في رفع معدلات النمو الاقتصادي من خلال التنوع الاقتصادي في مصادر الدخل القوي للاقتصاد اذ يعد التكوين الرأسالي الثابت المكون الرئيسي للاستثمار في أي كيان اقتصادي، 


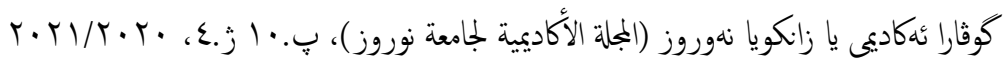

اختبار ديكي ـ فولر المطور: قام ديكي_فولر عام 1981 بتطوير اختبار

جذر الوحـدة يـدعى ديكي_ فولر الموسع باسـتخدام متغـير ذو إبطـاء

المتغيرات المفسرة وتوصل الى نتيجة معالجة نقطة الضعف التي يعاني منها

اختبار ديكي_ فولر البسيط المتثلة بشكلة الارتبـاط الناتي في حد الخطأ،

مما جعله أكثر دقة وكفاءة من اختبار ديكي_ فولر البسيط.

2- اختبار فيليس- بيرون: ان اختبار فيلبس بيرون لاختبار استقراريه

السلاسل الزمنية، يعطي احصائيات اكثر دقة من اختبار ديكي فولر كما

ويعتمد على طريقة إحصائية غير معلميـة في تصحيح الارتبـاط الناتي في

بواقي معادلة اختبار جذر الوحدة. اختبار (PP) يملك نفس توزيح اختبار

والفرضيات نفسها ( (ADF)

5.4 التكامل المشـرك باستخدام أنمـوذج الانحـدار الذاتي للإبطاء المـوزع

Autoregressive Distributed Lag Estimate ) (ARDL)

Engle يدم القياس الاقتصادي منجيات عديدة لاختبار النكمل المشترك ومنها Granger1987,Johansen1989, Johansen\& Juselius1990 and

وتشـرط هذه المنهجيات أن نكون المتغيرات محل الدراسة متكاملة من نفس

الرتبة، يضاف الى ذلك ان نتأجُ تقدير العينات الصغيرة تعطي تقديرات غير دقيقة

مما يدعو الباحث لاختيار مـا يتلاهم مع الأموذج والعينة المراد تقديرها، وعليه

سيتم في هذا البحث اعتماد منهجية (ARDL) المطورة من قبل( Pesaran

1997 \& Shinand 2001 للتقدير حيث توفر مرونة اكثر في الاستخدام

نظرا لعدم اشتراطها التقيد بدرجة نكامل المتغيرات فسواءوأكانت من الرتبة (1) أم الرتبـة I(0) فانه بالإمـكان اجراء التكامـل المشترك لها، شريطة التأكدـ مـن استقراريه السلاسل الزمنية لمتغيرات الدراسة في الدرجة الصفر والدرجة الوولى وليس في الدرجة الثانية، بالتالي اجراء النكامل المشترك دون قيد، يضـاف الى لى ذلك فان منهجية (ARDL) تتمع بزايا عديدة منها امكانية اعتماد التقدير للمديين

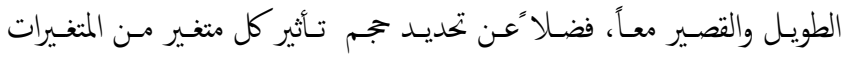
المستقلة على المتغير التابع مع تقديم النتائج الافضل للمعلمات في الأجل الطويل الى لى جانب مزايا اخرى (Gujarati,2005, 62-64). وعلى وفق ما تم عرضه سيتم تقدير اثر الانفاق العسكري في تكوين راس المال الثابت لعينة البحث ومن خلال استخدام الاختبارات الاتية:-
LCA اللوغاريتم الطبيعي لإجلالي تكوين راس المال الثابت للسعودية وللمدة $.2018-1980$ LGM

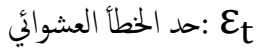

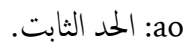

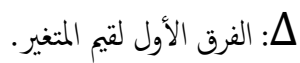
B1,B2 . R,N عدد فترات الابطاء الزمني الامثل للأثموذج. Ui اضافة الى الاعتاد على المتغير العشوائي الذي يفسر التأثيرات العشوائية اللمتغيرات التي لم تدخل في الانموذج وذلك لأجل تحويل الصيغة الرياضية إلى صيغة قياسية (Pesaran, 1997, 5) . 3.4 الطرق القياسية والكمية المعتمدة في التقدير في هذا البحث تم الوعتاد على بيانات السلاسل الزمنية كونها من اكثر البيانات استخداماً في الدراسـات التطبيقية، فالسلسـة الزمنية هي بموعة مـن المعطيـات ممثلة عبر الزمن المرتب ترتيبا تصاعديا إذ تتكون مـن بموعة مـن المركبات التي تساعد الباحث في معرفة سلوك السلسلة وتحديد مقدار تغيراتها وادراك طبيعتها واتجاهها بهدف اجراء التقدير والتنبؤ لها (محد، 2012، 195). 4.4 اختبار استقراريه السلاسل الزمنية : قبل البدء بتقدير الانموذج يتطلد التاكد من خلو السلاسل الزمنية لمتغيرات Unit ） البحث من مشكلة عدم الاستقراريه المثتأتية من وجود جذر الوحدة (root اجل الوصول الى أفضل تقديرات للعلاقات الدالية بين المتغيرات الاقتصادية، سنتمد في بكثتنا على أهم الاختبارات المعتمدة لدى الباحثين وها (اختبار ديكي _ فولر الموسع واختبار فيليس - بيرون ) وبالتسالي سوف نتحقق من استقرارية السلاسل الزمنية عن طريق هذين الاختباريبن. 


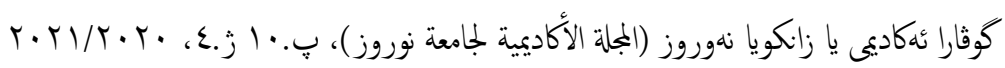

جدول (3) اختبار سكون سلسلة الانفاق العسكري بالفرق الاول للمدة (1980-2018)

\begin{tabular}{|c|c|c|c|c|c|c|c|c|}
\hline \multicolumn{4}{|c|}{ نيليس- بورن } & \multicolumn{5}{|c|}{ ديكي ثولر المطور } \\
\hline rank & الامتالية & القهية المرهة & القهمة المسوهة & الكمتلية & & القهمة المرهة & القية المسوهة & الr \\
\hline \multirow[t]{4}{*}{ 1(1) } & 0.0000 & (")-2.945842 & -6.934771 & 0.0000 & $5 \%$ & & -6.410203 & كابت نقط \\
\hline & & (")-2.611531 & & & $10 \%$ & & & \\
\hline & 0.0000 & (")-3.540328 & -7.199840 & 0.0713 & $5 \%$ & -3.562882 & -3.388853 & بوجود كابت \\
\hline & & (")-3.202445 & & & $10 \%$ & -3.215267 & & والجاه كام \\
\hline
\end{tabular}

المصدر : من اعداد الباحثتان بالاعتاد على برنامج Eviews10

-

وكما موضح في الجدول (3)، توضح نتائُ استقراريه السلاسل الزمنية ومن خلال اختبار(PD ADF)، وبعد اعتماد الفرق الأول ان السلسلة الزمنية استقرت، مما يعني عدم وجود جذر وحدة لسلسلة متغير الانفاق العسكري(CA) وعليه فان سلسلة المتغير المذكور مستقرة عند الفرق الأول (1)، (بوجود الثابت، وجود ثابت مع التجاه عام)، ونستدل من قيمة الاحتمالية prob بانها أقل من (5\%) مما يعني قبول الفرضية البديلة والتي تنص بعدم وجود جذر وحدة، وبالتالي ان جميع السلاسل الزمنية لمتغيرات دراستنا في الأموذج المقدر لا تحتوي على جذر وحدة ومستقرة.

2.5.2 اختبار وجود مشكلة الرتباط الناتي للحكم على صلاحية الأنموذج وملائمته، سنعتمد على بعض اختبارات التشخيص، للتأكد من مدى تخطي الانموذج للاختبارات القياسية، وذلك لبيان وجود او عدم وجود مشاكل قياسية تؤثر على نتائُ الاختبار، وسنبدأ باختبار الارتباط الذاتي المتسلسل وكما هو موضح في الجدول(4) الذي يبين لنا نتاجُ اختبار الارتباط

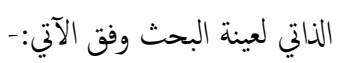

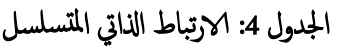

$\begin{array}{llll}\text { F-statistic } & 2.040212 & \text { Prob. F(2,31) } & 0.1471\end{array}$

المصدر - من اعداد الباحتان بالاعتاد على تخرجات برنامج

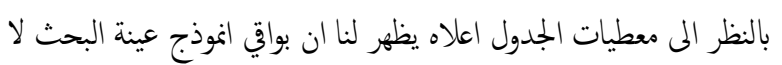

تعاني من مشكلة الارتباط الذاتي المتسلسل لحد الخطأ، اذ بلغت القيمة الاحتالية (0.1471)، وهي اكبر من(5\%) و عليه سنقبل بفرضية العدم التي تنص على ان البواقي لا تضضمن مشكة الارتباط الذاتي لحد الخطأ.

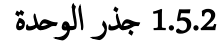

يظهر الجدول(2) نتاجُ اختبار ديكي فولر وفيليس بيرون لبيان سكون المتغير المستقل الانفاق العسكري والمتغير الممتمد تكوين راس المال الثابت في السعودية

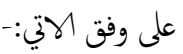

الجدول 2: اختبار سكون السلسلة الزمنية للانفاق العسكري وتكوين راس المال الثابت للمدة (1980-2018)

\begin{tabular}{|c|c|c|c|c|c|c|c|}
\hline \multicolumn{5}{|c|}{ بيليس- يورف } & & \multicolumn{2}{|c|}{ ديكيج - فولر المطرو } \\
\hline rank & r r r الية & 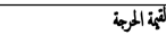 & القهة الطصية & المهنالية & القئ المرهة & القية الطونة & T \\
\hline \multicolumn{8}{|c|}{ اثمأ السكري (GM) } \\
\hline \multirow[t]{4}{*}{$1(0)$} & \multirow[t]{2}{*}{0.2700} & (") -2.943427 & \multirow[t]{2}{*}{-2.038142} & \multirow[t]{2}{*}{0.2661} & () -2.943427 & \multirow[t]{2}{*}{-2.047960} & \multirow[t]{2}{*}{ ثايت قط } \\
\hline & & $(")-2.610263$ & & & (") -2.610263 & & \\
\hline & \multirow[t]{2}{*}{0.2891} & (")-3.536601 & \multirow[t]{2}{*}{-2.584365} & \multirow[t]{2}{*}{0.2891} & (1)-3.536001 & \multirow[t]{2}{*}{-2.584365} & \multirow{2}{*}{ والجاه كام } \\
\hline & & (")-3.200320 & & & (") -3.200320 & & \\
\hline & & & \multicolumn{3}{|c|}{ (CA) تكون راس المال الثائ } & & \\
\hline \multirow[t]{4}{*}{$1(0)$} & \multirow[t]{2}{*}{0.0000} & $\left({ }^{(}\right)-2.9443427$ & \multirow[t]{2}{*}{-7.255520} & \multirow[t]{2}{*}{0.0000} & $(7)-2.943427$ & \multirow[t]{2}{*}{-8.484932} & \multirow[t]{2}{*}{ كايت قط } \\
\hline & & $(")-2.610263$ & & & $(")-2.610263$ & & \\
\hline & \multirow[t]{2}{*}{0.0000} & $\left({ }^{(*)}-3.536601\right.$ & \multirow[t]{2}{*}{-9.093613} & \multirow[t]{2}{*}{0.0000} & (")-3.536601 & \multirow[t]{2}{*}{-9.093613} & \multirow{2}{*}{ 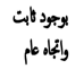 } \\
\hline & & $(")-3.200320$ & & & (") -3.200320 & & \\
\hline
\end{tabular}

المصدر : من اعداد الباحثتان بالاعتاد على برنامج Eviews10

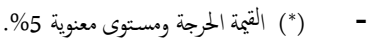

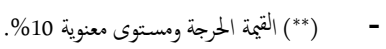
- منزة الابطاء هي اتوماتيكي. يوضخ الجدول (2) اعلاه اختبار كل من ADF و PP مPكل لسلسلة المتغيرين الانفاق العسكري (GM) والنكوين الرأسـالي الثابـ (CA)، إذ ان سلسـة الانفـاق العسكري لم تكن مستقرة عند المستوى الاصلي اي عند مستوى (0)1، في حالة وجود (ثابت فقط، وبوجود ثابت واتجاه عام ). كما ان القيم المحسوبة لاختبار جذر الوحدة للانفاق العسكري هي أكبر من القيمة ونم الحرجة عند مستوى معنوية (5\%و 10\%)، في الحالات اعلاه ، مما يشير الى كي عدم استقراريه السلسلة الزمنية للانفاق العسكري، وعليه سـنقبل بفرضية العدم التي تنص على وجود جذر الوحدة للسلسلة الزمنية، ونرفض الفرضية البديلة. أما فيا يخص سلسلة إجلالي تكوين راس المال الثابت (CA)، فقد تبين من ننائُ الاختبار بانها مستقرة عند المستوى الاصلي اي عند مستوى (0)1، في حالة وجود (ثابت فقط، وبوجود ثابت واتجاه عام )، وان القيم الخمسوبة لاختبار جذر الوحدة للانفاق العسكري هي أصغر من القيمة الحرجة عند مستوى معنوية (5\% و10\%)، كما في جدول اعلاه، وهذا يدل على استقراريه السلسلة الزمنية لتكوين رأس المال الثابت، وبالنالي نرفض فرضية العدم ، ونتبل بالفرضية البديلة التي تنص على عدم وجود جذر وحدة. 


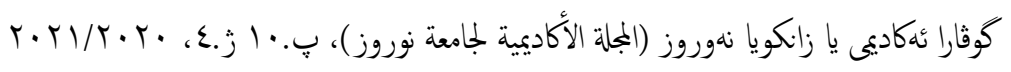

يستخدم اختبار الحدود للتأكد من وجود علاقة توازنية طويلة الاجل بين

المتغير التابع والمتغير المستقل، ووفقا لمعطيات الجدول (6) تبين لنا وجود تكامل مشترك بين الانفاق العسكري (GM) مع إجلالي تكوين رأس المال الثابت (CA) في المدى الطويل إذ من خلال احتساب احصائية فيشر يتم اتخاذ القرار بشأن فرضية العدم التي تشير انه لا توجد علاقة تكلمل على المدى الطويل، اعتماداً على مقارنة قيمة (F) المسوبة التي بلغت (24.06045) مع الحدود الدنيا والعظمى، فاذا كانت قيمة احصائية فيشر (F) المحتسبة اكبر من القيمة العظمى يتم رفض فرضية العدم اما اذا كانت اصغر من القيم الدنيا يتم قبول فرضية العدم اما اذا وقعت ما بين القيم العظمى والدنيا سيتم اتخاذ القرار وفقا لنتائج معامل تصحيح الخطأ (Nkoro \& Kelvin, 2016:80) ووفقا لقمة احصائية فيشر (F) التي اظهرتها نتائُ اختبار الحدود فهي أكبر من قيمة الحد الاعلى اللقيم الحرجة مما يدل على وجود علاقة تكامل مشترك في المدى الطويل بين متغيرات الأموذج.

6.5.2 تقدير انموذج حد تصحيح الخطأ

يمثل هذا الأموذج صيغة الفرق الوول زائداً هد تصحيح الخطأ وتباطؤ لفترة زمنية واحدة ويرمز له LCA LCA وفي البحوث التطبيقية يتم الاستعانة به للميز ما بين المدى الطويل والقصير حيث ان القيمة التوازنية لمتغيرات الاتموذج تتحدد من خلال العلاقة التوازنية طويلة الوجل لنستدل من ذلك في معرفة المدة الزمنية التي تستغرق للتعديل من الاجل القصير الى التوازن طويل الاجل. اي انه يقيس سرعة عودة الاختلال في الامد القصير باتجاه التوازن طويل الأمد، ويتطلب ان تكون قيمة الاحتالية معنوية وعادة تكون اثارته سالبة لأنه يشير المعدل الذي

تتجه به العلاقة القصيرة نحو العلاقة طويلة الاجل وفيا يخص انموذج البحث فان حد تصحيح الخطأ ظهر معنويا واشارته سالبة، ليدل ذلك على وجود تكامل مشترك بين الانفاق العسكري وإجالي تكوين راس

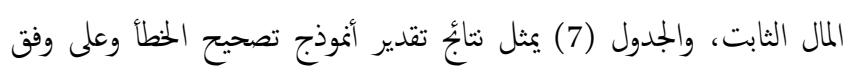

الجدول 7: نائج مقدرات العلاقة قصيرة الآجل بين الأفاق العسكري وإجالي تكوين راس المال الثابت المدة (1980-2018)

\begin{tabular}{cccc}
\hline \hline Variable & Coefficient & t-Statistic & Prob \\
\hline C & 2.540765 & 6.655403 & 0.0000 \\
\hline LCA(-1) & -0.619839 & -6.348978 & 0.0000 \\
\hline LG(-1) & -0.245817 & -2.524796 & 0.0166 \\
\hline D(LG) & 0.309363 & 1.759887 & 7700.0 \\
\hline \hline & Eviews10 المدراد
\end{tabular}

3.5.2 اختبار مشكلة عدم التجانس

اظهرت نتائُ اختبار مشكلة عدم تجانس التباين إن قيمة(F) الاحتالية، قد بلغت

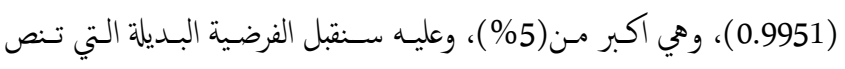

بتجانس البواتي وخلوها من اختلاف التباين كما هو مبين في الجدول (5):الجدول 5: مشكلة عدم التجانس

\begin{tabular}{|c|c|c|c|}
\hline F-statistic & 0.023258 & Prob. F(3,30) & 0.9951 \\
\hline
\end{tabular}

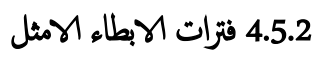

تم اختيار فترة الابطاء الامثل من خلال اقل قيمة لفتزة ابطاء لمعيار اكيكاي

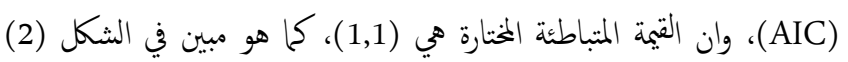
وبعد تحديد فترة الابطاء سنبدأ بالخطو التالية وهي تقدير أنموذج تصحيح حد الخطأ. Akaike Information Criteria

19.92

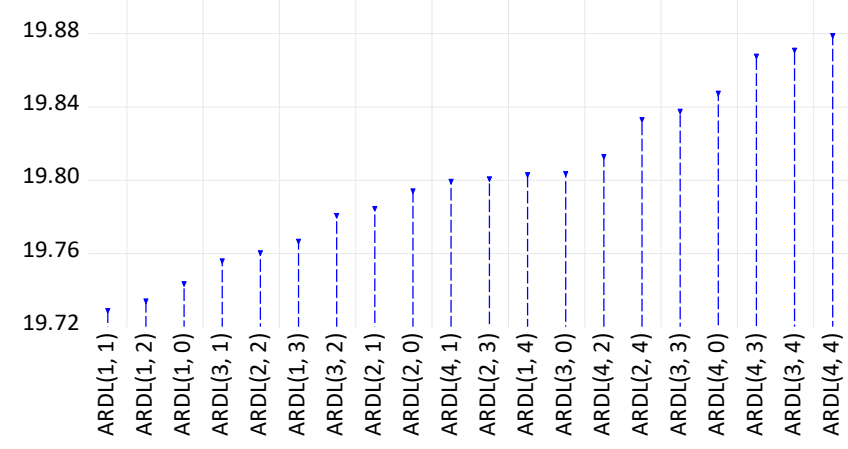
Eviews 10 المصدر من اعداد الباحثتان بالاعتاد على مخرجات برنامج

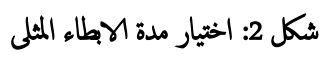

5.5.2 نابجُ اختبار النكامل المشترك بين متغير الانفاق العسكري وتكوين راس مداء المال الثابت باستخدام منهج الحدود للمدة 1980-2018 الجدول (6) التكمل مشترك بين متغير الانفاق العسكري ومتغير تكوين راس المال الثابت باستخدام أثموذج ARDL (منهجية المدود)

(F)

\begin{tabular}{|c|c|c|c|}
\hline وجود لكل & \multicolumn{2}{|c|}{24.06045} & الانموذج \\
\hline مشترك بين الانفاق & الحد الهدنى & الحلى & القيم الحرجة \\
\hline تكوين راس المال & 4.04 & 4.78 & $\% 10$ \\
\hline الثابت عند مستوى & 4.94 & 5.73 & $\% 5$ \\
\hline معنوية 5\% & 6.84 & 7.84 & $\% 1$ \\
\hline
\end{tabular}

المصدر - من اعداد الباحثتان بالاعتاد على مخرجات برنامج 


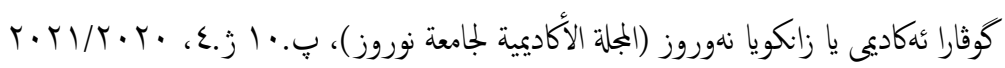

بعقدار وحدة واحدة يؤدي إلى انخفاض إجالي تكوين راس المال الثابت بعقدار

\subsection{2 اختبار الاستقرارية}

الخطوة الاخيرة هي اختبار الاستقرارية (stability) الهيكلي للأثموذج المقدر للمعلمات في المديين القصير والطويل خلال مدة البحث لتقدير انموذج الانحدار الذاتي ذي الاتجاهات المتباطئة ويتم ذلك باستخدام اختبار الجمموع التراكي للبواقي

The cumulative sum of the recursive ) CUSUM المتابع residuals )، وقد تم تطويره من قبل Brown et al فني حالة عدم وقوع الرسم البياني (CUSUM) وعند مستوى معنوية (5\%)، داخل حدود المنطقة الحرجة، سيدل ذلك على ان جميع المعلمات غير مستقرة حسب ما نصت عليه الفرضية البديلة وبالنظر الى الشكل (3) نجد ان اختبار الاستقرارية لم يقع داخل الحدود الحرجة ويعزى ذلك المى التقلبات التي تعرض لها الاقتصاد السعودي من اثار حرب الخليج في فترة التسعينات وكذلك الازمات المالية العالمية في 1998، و 2008، وهذا يدل على عدم استقرارية المعلمات في الاجلين القصير والطويل في اختبار المجموع التراكمي لبوايق المتابع للأثموذج المقدر (ARDL) للسعودية.
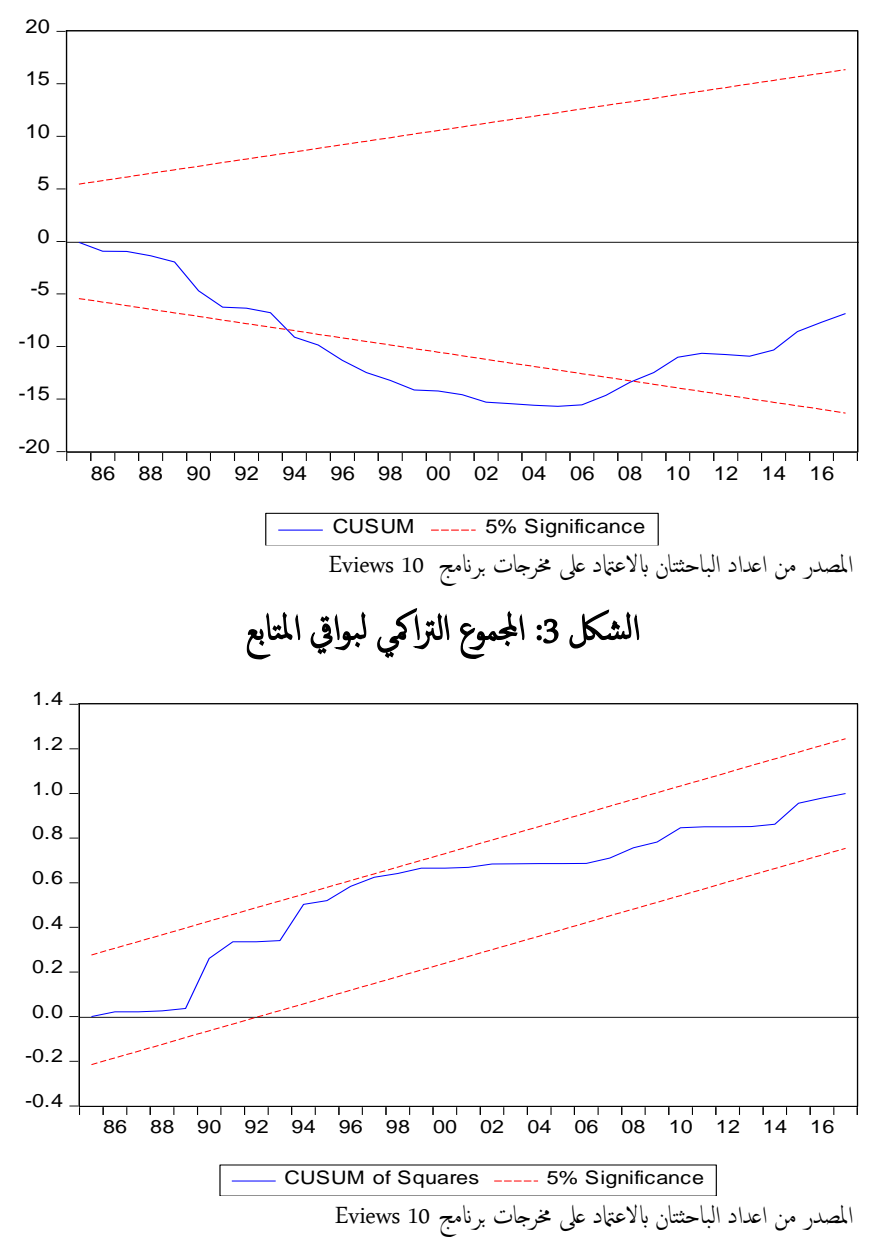

الشكل (4) الجمموع التراكي لمربعات البواتي المتابعة
يين الجدول(7) نتاجُ أنموذج تصحيح حد الخطأ والمعلمات قصيرة الأجل للانفاق العسكري وإجالي تكوين راس المال الثابت، حيث كان افضل اختيار للأثموذج في برنامج Eviews10 هو الاختيار( الثابت)، وقد تبين من النتاجُ المثثتة في الجدول (7) ان الانفاق العسكري في السعودية يؤثر في اجلالي تكوين راس المال الثابت لفترة واحدة متباطئة زمنية (LG(-1))، لذلك جاءت إثارته سالبة اذ بلغت (0.245817-)، بعنى ان انخفاض الانفاق العسكري بوحدة واحدة سيؤدي إلى ارتفاع إجالي تكوين راس المال الثابت بمقدار( 0.24- \%). وفيا يخص معامل حد تصحيح الخطأ (معلمة المتغير التابع CA ولفنزة ابطاء واحدة) LCA(-1) فان معامل المرونة قدر ب (-0.619839-) و جاءت اثارته سالبة ومعنوية، إذ بلغت قيمة الاحتالية (0.0000)، وبها فان سرعة العودة إلى الوضع التوازني طويل الاجل هي (0.61\%)، وعند أخذ مقلوب قيمة المعلمة (LCA)، وهي (1.613) يتم معرفة المدة الزمنية المطلوبة للعودة إلى الوضع التوازني ووفق المعطيات التي توصلنا اليها تبين لنا ان المدة اللازمة تكون بعد سنة وسبعة اشهر و10 ايام، لتجاوز الصدمة بشكل كامل في الاجل القصير.

7.5.2 تقدير العلاقة طويلة الأجل تثثل هذه المرحلة تقدير معلمات الاجل الطويل من خلال اختبار أنموذج (ARDL) المستقل الانفاق العسكري، والمتغير الممتمد إجالي تكوين راس المال الثابت

$$
\text { لعينة البحث وكالاتي:- (CA,GM) }
$$

الجدول(8) نتاجُ تقدير العلاقة طويلة الأجل بين المثغيرات الاقتصادية للسعودية للمدة

(2018-1980)

\begin{tabular}{cccc}
\hline \hline Variable & Coefficient & t-Statistic & Prob \\
\hline LG & -0.396582 & -2.312860 & $\mathbf{0 . 0 2 7 1}$ \\
\hline
\end{tabular}

المصدر: من اعداد الباحثتان بالاعتماد على مخرجات برنامج Eviews10 يظهر لنا الجدول(8) تقدير العلاقة طوياة الأجل لمعامل المرونة للانفاق العسكــري (LG)، إذ بلغـت (0.396582-) في الاجل الطويل وذات علاقة عكسية في إجلالي تكوين راس المال الثابت في السعودية وجاءت إثارته متطابقة مع إثارة معامل المرونة لمتغير الانفاق العسكري (LG) في الاجل القصير وبلغت Prob (0.0271)، وذات تأثير معنوي على إجلالي تكوين راس المال الثابت (CA) ووفقا لذلك سنرفض فرضية العدم التي تتضمن عدم وجود علاقة توازنية طويلة الأجل ونتمد الفرضية البدية، أي أن ارتفاع الانفاق العسكري 


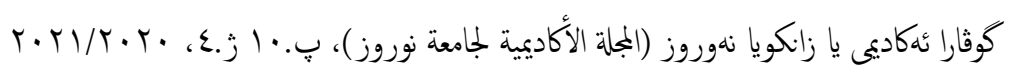

تبين لنا من خلال تحليل مـا تم عرضه مـ بيانات لمتغيرات الانموذج ان العلاقة ما بين متغير التكوين الرأسمالي والانفاق العسكري علاقة عكسية وان تطور وزيادة حصة التكوين الرأسالي الثابت من الناتج المحلي الاجهالي يعمد وبشكل مباشر على نسبة ما هو مخصص للانفاق العسكري، التي اخذت تتزايد بمعدلات اعلى من تزايد نسبة التكوين الرأسمالي للعديد من

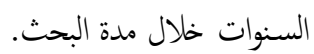

يستأثر الاقتصاد السعودي بثروات طبيعية كبيرة، وخصوصا من النفط الخام، مما جعله يعتمد على العوائد النفطية في تمويل الانفاق العام، وهذا مـا عرضه لصدمات أسعار النفط من ناحية وللتحولات الجيوسياسية والدولية من ناحية اخرى. ليزيد بذلك من الاختلالات الهيكلية التي من شانها اعاقة عملية التنمية الاقتصادية.

تبين من خلال ما يتم رصده من مبالغ لاستيراد الاسلحة والذخائر، ومن قدرة البلد على التصنيع التي لا تتجاوز 2\% وفق احصائيات مؤسسة النقد السعودي ان القطاع العسكري في السعودية يساهم في التجارة الخارجية للأسلحة كستورد فقط وهذا ما يتزتب عليه نتائج سلبية على الميزان التجاري ضمن ميزان المدفوعات اضافة الى ان التوسع في التسليح لم يساهم في خلق فرص عمل بالقدر الكافي لتخفيف البطالة ، نظرا لانخفاض ما يتم انتاجه من اسلحة محليا والاعتماد شبه الكلي على الاستيرادات التي تشكل

$$
\text { تسربا للدخل القومي. }
$$

تشكل الايرادات النفطية الجزء الاكبر من الايرادات العامة للسعودية وعلى وفق ذلك فان التغير في الانفاق العام يعتمد على حجم الايرادات لكن فيا يخص السعودية فان ارتفاع أو انخفاض الإنفاق العسكري لسنوات عديدة لم يكن له علاقة بالإيرادات العامة نظراً لخضوعه لعوامل سياسية الى لى حد كبير واعتماده على مصادر التمويل الاخرى كالقروض. الحرب في اليمن والفشـل في التوصل الى حل سلمي لانهائها، استتنزفت الكثير من طاقة السعودية المالية خاصة في ظل التقلبات الحاصلة في اسعار النفط نظرا لاعتاد الاقتصاد السعودي بشكل كير على الايرادات النفية، التي تشكل 43\% مـن النـاتج المحلي الاجهالي ليـأتي ذلك على حسـاب الاهمية النسبية للعديد من المتغيرات بما فيها النكوين الرأسمالي الثابت .
وبالنظر الى الشكل(4) نرى بان الرسم البياني قد وقع ضمن حدود المنطقة الحرجة لاختبار (Cusum of squares) وعند مستوى معنوية 5\% وهذا يعني حسب فرضية العدم بان المعلمات مستقرة ومقبولة، وان اختبار الاستقرارية يقع داخل الحدود الحرجة وتتغاير حول القيمة الصفرية (الصفر)، ليدل ذلك على استقرارية المعلمات في الاجلين القصير والطويل حسب الاختبار الاحصائي للأموذج المقدر (ARDL) للسعودية.

\section{3. - الاستناجات والمقترحات}

بالاستناد إلى ما تم عرضه ضمن الجانب النظري والتطبيقي وما توصل اليه البحث من نتاجُج ، تم اعتماد هذه الاستناجات والمقترحات وعلى النحو الآتي:-

1.3 الوستناجات

1.1.3 استناجات الجانب النظري

لقد افرزت الاحداث السياسية والاقتصادية غير المستقرة في منطقة الشرق الاوسط وشمال افريقيا منذ عقد الثانينيات ازمات داخليه وخارجية للسعودية، مما ادى الى نشوء الممضلة الامنية الامـر الذي دفع السعودية لخوض سباق التسلح لتقوية مركزها اقليما ودوليـا من خلال بناء ترسانة عسكرية من جهة وتخصيص مدفوعات مالية شبه دورية للدول والاطراف ذات النفوذ ومنها الولايات المتحدة لحماية مصالحها في المنطقة . ان ما ترصده المملكة العربية السعودية سنويا من مبالغ ضخمة لتخصيصات الدفاع والانفاق العسكري يكون على حسـاب الإنفاق على الحاجـات الإنسانية للافراد من صحة وتعليم هذا من ججة ومن جهـة اخرى فان هذا الانفاق اثقل موازتها العامة مما تسبب في هدر للكثير من الاموال ليؤثر بذلك على التكوين الراسهالي الثابت ومن ثم على معدل النمو الاقتصادي

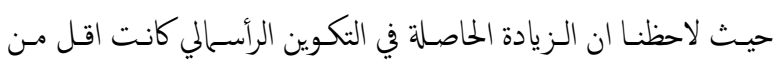
الزيادة المخصصة للانفاق العسكري. تبين من خلال ما تم عرضه وتحليله من بيانات ان امكانيات السعودية في زيادة انفاقها العسكري في ظل هبوط اسعار النفط او انخفاض الايرادات تتم من خلال ترشيق النفقات الاستثقرية والتنموية مـا يزيد من الاختلال الهيكلي لقطاعات الاقتصـاد القومي. ووفقـا لذلك فـن الصعب النهوض بالقطاع المدني دون ان يتم ضبط وترشيق النفقات العسكرية لخلق توازن بين القطاعين وفقا للاهمية النسبية . 


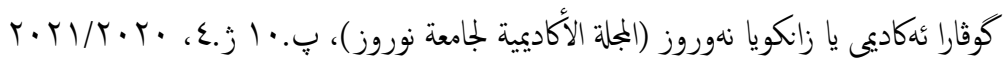

النفطية في اقامة صناعات محلية لصنيع ما تقكن من انتاجه محليا بدلا من الاستمرار في استيراده لتقليل العبء الاقتصادي.

يتطلب من السعودية الاسراع بتطبيق سياسة اصلاحية حقيقية تهدف الى احداث تغيير فعلي شامل وخطط في الواقع السعودي تجنبـا للكثير من الازمات. والسعي الجاد نخو التحول الديمقراطي، وبناء الدولة، وتنمية المجتع المدني، و تعزيز المو الاقتصادي. العمل على توسيع وتنويح الروابط بين القطاعين العسكري والمدني عبر خطط تهدف المى استثمر القدرات المحلية و خلق فرص عمل في صناعات

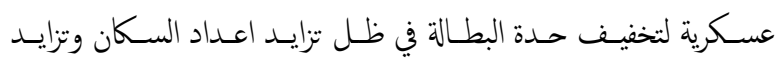

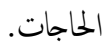

يتوجب على السعودية العمل على تحقيق بئة مستقرة اقتصادياً وسياسياً اعتمادا على قدراتها الاقتصادية وعلى مـا يتوفر لديها من موارد طبيعية وبشرية- اذا مـا تم استخداتها وتوجيهـا بشكل كفوء -بالاسـتفادة مـن الفوائض المالية المتحققة عند ارتفاع اسعار النفط لتحفيز الاستثمار المحلي والاجنبي بدلا مـن السعي الم امتلاك ترسانة عسكرية تستنزف امواله وتزيد من كلفة الفرصة البديلة وتهدد استقراره الداخلي .

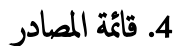

1.4 الثقارير والنشرات العربية والدولية

1. الام المتحدة، تقريـر الخبراء الحكوميين حول الصـلة بين نزع السـلاح والتنمية في السياق الدولي الراهن ، نيويورك، 2004 2. صندوق النقد الدولي، المملكة العربية السعودية معالجة التحديات الاقتصادية الناشئة للحفاظ على النمو، متوفر على الرابط الاتي: www.imf.org/mrdia/website/IMF/imported 3. الكتاب السنوي لمعهد ستوكهولم لدراسات السلام اعداد متفرقة للسنوات 1985-2019 متوفر على الرابط الاتي: و https://www.sipri.org/yearbook/2019 www.sipri.org/research/armament-anddisarmament/arms-and-military-expenditure/militaryexpenditure 4. النشرات الاحصـائية لمؤسسـة النقــد السعودي اعـداد مختلفـة للاعوام

$$
\text { 2019-1980 منشورة على الموقع الككتروني. }
$$

ان الانفاق العسكري قد اتخذ منحى تصاعدي ومسيتمر وهذا يشـير الى زيادة عبء الانفاق العسكري لايقتصر على الاستثار والتكوين الرأسمالي وانمـا سـيزيد مـن العبء الاجتماعي نظرا لان الزيادة الحاصلة في ميزانيـة الانفاق العسكري تكون على حساب العديد من متغيرات الاقتصاد الكلي. 2.1.3 - 2.3 استناجات الجانب التطبيقي

تبين من خلال اختبار ديكي فولر وفيليبس بيرون، ان الانفاق العسكري (GM) ،للسعودية للمدة (1980-2018)، احتوى على جذر وحدة، بيد انه اصبحت السلسلة ساكنة بعد اخذ الفرق الأول، إما إجهالي تكوين راس المال الثابت(CA) فكانت السلسلة مستقرة وساكنة عند المستوى · الهلي أظهرت نتائُ البحث ان هنالك علاقة توازنيـة قصيرة الآجل، حيث ان معلمة المتغير التابع (CA) في السعودية ولفترة ابطاء واحدة قدرت بــ (0.619839)، وبالتـالي يلزم العودة إلى الوضع التوازني بعد سـنة وسـبعة اشهر و10 ايام ، أي هو الزمن اللازم لتجاوز كامل الصدمة في الاجل

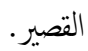
اكد البحث وجود علاقة توازنية طوياة الأجل بين المتغير المستقل الانفاق

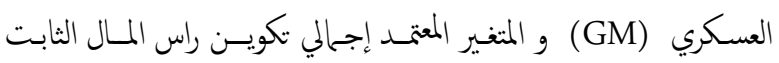
(CA)، إذ بلغ معامل المرونة للانفاق العسكري في الآجل الطويل ب(-

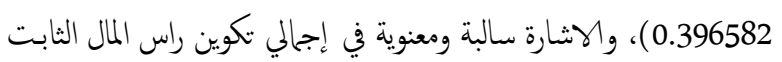
اي ارتفاع الانفاق العسكري بمقدار وحدة واحدة يؤدي الى انخفاض إجالي تكوين راس المال الثابت بعقدار(0.39\%) وهذه العلاقة تتوافق مع

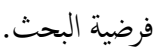
- 2.3 ضرورة العمل على تنويع مصادر الدخل لتقليل الاعتماد على ريع النفط وتهيئة البيئة الملائمة لنمو الاستثمرات المحلية والاجنيـة لتساهم في خلق فرص عمل وزيادة الطاقة الانتاجية. طالما ان الانفاق العسكري يشكل اهية نسية عالية ضمن هيكل الانفاق العام ونظرا لتزايد حصته من الناتج المحلي، عليه سيكون من الافضل توسيع نطاق الصناعات العسكرية القائمة والعمل على استخدام الايرادات 


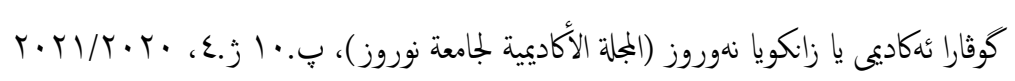

Economics of Peace and Security Journal, EPS Publishing, vol. $8(1)$.

9. M Ensar Yesilyurt \& J Paul Elhorst,2017, Impacts of neighboring countries on military expenditures: A dynamic spatial panel approach, journal of Peace Research2017, Vol. 54(6)

10. MEYER Francois \& SANUSI Abimbola ,2019 A CAUSALITY ANALYSIS OF THE RELATIONSHIPS BETWEEN GROSS FIXED CAPITAL FORMATION, ECONOMIC GROWTH AND EMPLOYMENT IN SOUTH AFRICA, STUDIA UNIVERSITATIS BABEȘ-BOLYAI OECONOMICA, VOLUME 64, ISSUE 1.

11. Peace Economics, Peace Science and Public Policy, Vol. 20, Issue 4.

12. Rahman, Taimur 2019, The Effect of Military Spending on Economic Growth in the Presence of Arms Trade: A Global Analysis

https://papers.ssrn.com/sol3/papers.cfm?abstract_id=3401331

13. HYPERLINK

"https://www.researchgate.net/profile/Rizgar_Abdlaziz" Rizgar Abdlkarim Abdlaziz,

HYPERLINK

"https://www.researchgate.net/scientific-contributions/NAM-

Naseem-2147299886" N.A.M. Naseem\& HYPERLINK "https://www.researchgate.net/profile/Ly_Slesman" Ly Slesman 2020, The Impact of Oil Price Shocks on the Military Expenditure of Selected MENA Oil Exporting Countries: Symmetric and Asymmetric Co-Integration Analysis, https://www.researchgate.net/publication

14. Ron P Smith, \& J. Paul Dunne, 2019, , Military Expenditure Growth and Investment, Journal HYPERLINK "https://www.tandfonline.com/toc/gdpe20/current" Defence and Peace Economics Volume 3 Received.

15. HYPERLINK

"https://www.sciencedirect.com/science/article/pii/014759678090 0505"Ronald PSmith, 1980, Military expenditure and investment in OECD countries, 1954-1973, HYPERLINK "https://www.sciencedirect.com/science/journal/01475967"Journa 1 of Comparative Economics HYPERLINK "https://www.sciencedirect.com/science/journal/01475967/4/1"V olume 4, Issue 1.

16. Saab , Bilal Y. 2014, THE GULF RISING Defense Industrialization in Saudi Arabia and the UAE, Brent Scowcroft Center on International Security at the Atlantic Council. https://www.files.ethz.ch/isn/182154/The_Gulf_Rising.pdf

17. Scheetz, T., 1991. The macroeconomic impact of defense expenditures: Some econometric evidence for Argentina, Chile, Paraguray and Peru. Defense Economics, 3. http://www.sama.gov.sa/ar-

$\underline{\text { sa/EconomicReports/Pages/YearlyStatistics.aspx }}$

$$
2.4 \text { البحوث والدوريات }
$$

$$
\begin{aligned}
& \text { 1. أحمد, إبراهيم. (2006). أثر إجلالي التكوين الرأسالي الثابت وعرض النقد على النشاط } \\
& \text { الإقتصادي. مجلة جامعة تشرين للبحوث والدراسات العلمية. }
\end{aligned}
$$

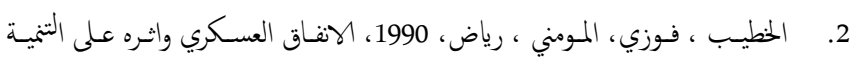

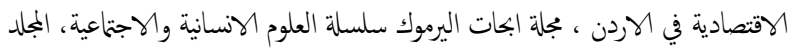

$$
\begin{aligned}
& 6 \\
& \text { 3. عطية، محمود صاح، 2011، اسباب زيادة النفقات العامة بين الفكر التقليدي والفكر } \\
& \text { الحديت، مجلة ديالى، العدد } 50 . \\
& \text { 4. كلكان، جواد كاظم، 2009، أبعاد الأمن الوطني ،ججلة المستقبل العراقي، العدد } 17 .
\end{aligned}
$$

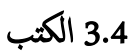

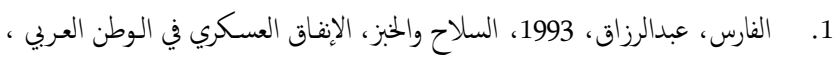

$$
\begin{aligned}
& \text { الطبعة الثالثة، بيروت، مركز دراسات الوحدة العربية . }
\end{aligned}
$$

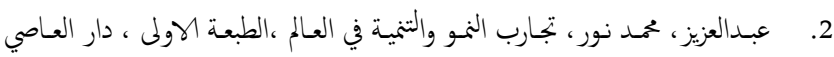

$$
\begin{aligned}
& \text { للمباعة والنشر والتوزيع، بيروت. }
\end{aligned}
$$

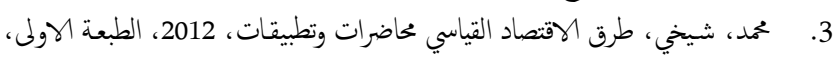

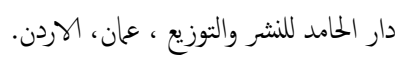

$$
\begin{aligned}
& \text { 5. المصادر الهنكلية }
\end{aligned}
$$

\subsection{Researches}

1. Chairil , Tangguh , 2013, Relationship between Military Expenditure and Economic Growth in ASEAN: Evidence from Indonesia, Journal of ASEAN Studies.

2. Chairil , Tangguh, 2013, Relationship between Military Expenditure and Economic Growth in ASEAN: Evidence from Indonesia, Journal of ASEAN Studies.

3. Chowdhury, A.R., 1991. Defense spending and economic growth. Journal of Conflict Resolu- tion, 35.

4. Collier, Paul, and Hoeffler, Anke 2009 Military expenditure in post-conflict societies, Economics of Governance, 7.

5. Daniel P. Hewitt Daniel P, 1991, Military Expenditure: International Comparison of Trends, IMF WORKINÍ; PAPER.

6. Gülbahar ÜÇLER, 2016, Testing the relationship between military spending and private investments: Evidence from Turkey, Theoretical and Applied Economics Volume XXIII (2016), No. 3(608), Autumn.

7. Hou, N., and Chen, B., 2014. Military Expenditure and Investment in OECD Countries: Revisited.

8. J. Paul Dunne \& Nan Tian, 2013. " HYPERLINK "https://ideas.repec.org/a/epc/journl/v8y2013i1p5-11.html" Military expenditure and economic growth: A survey," HYPERLINK "https://ideas.repec.org/s/epc/journl.html" 


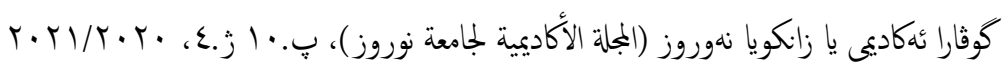

18. HYPERLINK "javascript:;" Seyfettin Erdoğan, HYPERLINK "javascript:;" Emrah İsmail Çevik \& HYPERLINK "javascript:;" Ayfer Gedikli 2020, Relationship between oil price volatility and military expenditures in GCC countries, HYPERLINK "https://link.springer.com/journal/11356" Environmental Science and Pollution Research volume 27.

19. Tangguh Chairil, Dedy S. Sinaga\& Annisa I. Febrianti 2013, Relationship between Military Expenditure and Economic Growth in ASEAN: Evidence from Indonesia, Journal of ASEAN Studies, Vol. 1, No. 2.

20. Yildirim, Julide, and Sezgin, Selami (2005) Democracy and Military expenditure: A Cross-Country Evidence, Transition Studies Review, 12.

\subsection{Books}

1. Gujarati ,Damodar, 2005 Basic Econometrics,5Th Edition ,New York.

2. Kozhan , Roman (2009) "Financial econometrics - with Eviews",

3. Nkoro, Emeka and Kelvin, Aham , 2016, 2016Autoregressive Distributed Lag (ARDL) cointegration technique: application and interpretation, Journal of Statistical and Econometric Methods, vol.5, no.4

4. Pesaran, M. Hashem, 1997, An Autoregressive Distributed Lag Modelling Approach to Cointegration Analysis, Department of Applied Economics, University of Cambridge, England, First Version: ebruary, 1995, Revised: January, 1997.

5. Wooldridge, Jeffrey M, 2013 Econometrics, Fifth Edition, United States of America. 